Int. J. Dev. Biol. 58: 469-483 (2014)

doi: $10.1387 / \mathrm{ijdb} .140148 \mathrm{gb}$

\title{
Segment formation in Annelids: patterns, processes and evolution
}

\author{
GUILLAUME BALAVOINE* \\ Institut Jacques Monod, CNRS / Université Paris Diderot, Paris, France
}

\begin{abstract}
The debate on the origin of segmentation is a central question in the study of body plan evolution in metazoans. Annelids are the most conspicuously metameric animals as most of the trunk is formed of identical anatomical units. In this paper, I summarize the various patterns of evolution of the metameric body plan in annelids, showing the remarkable evolvability of this trait, similar to what is also found in arthropods. I then review the different modes of segment formation in the annelid tree, taking into account the various processes taking place in the life histories of these animals, including embryogenesis, post-embryonic development, regeneration and asexual reproduction. As an example of the variations that occur at the cellular and genetic level in annelid segment formation, I discuss the processes of teloblastic growth or posterior addition in key groups in the annelid tree. I propose a comprehensive definition for the teloblasts, stem cells that are responsible for sequential segment addition. There are a diversity of different mechanisms used in annelids to produce segments depending on the species, the developmental time and also the life history processes of the worm. A major goal for the future will be to reconstitute an ancestral process (or several ancestral processes) in the ancestor of the whole clade. This in turn will provide key insights in the current debate on ancestral bilaterian segmentation.
\end{abstract}

KEY WORDS: segmentation, metamerism, annelid, evolution, teloblasts

\section{Introduction}

Segmentation is a fascinating morphological property of a number of animal phyla comprising a broad majority of animal species. Although speculations about its origin and evolution emerged as soon as the theory of evolution received widespread support in the second half of the nineteenth century, the subject has remained eminently contentious up to the present day. The key question asked is simple in appearance: was a form of segmentation of the anteriorposterior axis of the trunk present in the last common ancestor of bilaterians, an animal commonly referred to as Urbilateria? Yet, the answer to such a question is bound to be complex for a number of reasons. Much is at stake in the field of metazoan evolution. It matters a lot how Urbilateria, the forefather of a bewildering array of bilaterian body plans, actually looked like. The scenarios that led to the emergence of the body plan of each bilaterian phylum are going to be radically different depending on whether Urbilateria was a simple flatworm-like animal (as proposed decades ago by Libbie Hyman in her planuloid-acoeloid theory, 1951, see Hejnol and Martindale, 2008, for a modernized version) or an annelidlike segmented worm with a number of fully differentiated organ systems (the "complex" Urbilateria theory, Balavoine and Adoutte, 2003). In the former case, body plan emergence in bilaterians has involved mostly evolutionary convergences, supposedly selected for by strong and sustained selective pressures in favour of more "efficient" anatomies adapted to active life styles. In the latter case, evolution involved mostly differentiation of pre-existing systems of organs, with no need for multiple convergences. Urbilateria is also, crucially, an ancestor of the vertebrates. The question of the origin of the vertebrates is of course of particular interest to us and greatly dominates the field of animal evolution in terms of publication numbers. Yet, the debate on Urbilateriahas surprisingly little influence so far on the way vertebrate specialists address the question of the emergence of the chordates. Nevertheless, the "complex Urbilateria" theory goes against most of the traditional theories on the origin of vertebrates (Garstang, 1928; Berrill, 1955) in that many of the vertebrate complex organs systems would not need to have evolved ex nihilo, including the complex muscular and neural segmented patterns of their trunk.

Abbreviations used in this paper: SAZ, segment addition zone.

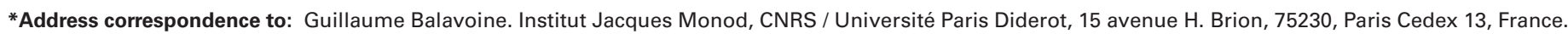

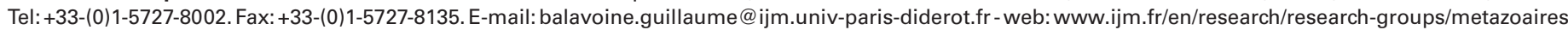


Three major arguments are cited to contradict the hypothesis of a metameric Urbilateria

- What is a segment? The answer to this question seems to vary according to the animal group considered because segmental units are not necessarily made of the same sub-structures (for a thorough discussion, see Scholtz, 2002). Is there really anything in common between arthropod metameres and the way a chordate is segmented? Classically, three major bilaterian groups are considered extensively metameric: the arthropods, annelids and vertebrates. Strong similarities have always been recognized between annelids and arthropods, to the point that these two groups were for two centuries grouped into a clade of the "Articulata" (Cuvier, 1817). This grouping was defended on the basis of shared external annulation, a pair of appendages on each segment and also internal repeated organs, in particular their ladder-like ventral nervous system with chains of ganglia. Metamery in vertebrates looks different in many respects. Three ensembles of organs show repeated structures without clear relationships between each other: the pharyngeal basket with its series of branchial arches, the embryonic rhombencephalon and the dorsal trunk and tail. The dorsal nerve cord of vertebrates is not organized in a chain of ganglia. Can we still have a common origin of segmentation when the organs displaying repetitions in extant groups are not the same?

- Important progress has been made on resolving the phylogenetic relationships between animal groups in the last two decades and this progress is considerably strengthened by recent phylogenomic studies (Dunn et al., 2008; Hejnol et al., 2009; Pick et al., 2010). The three main segmented groups, annelids, arthropods and chordates appear separated by large evolutionary distances. Each of these groups belongs to one of the solidly established "superclades" (trochozoans, ecdysozoans and deuterostomes respectively) and is more related to phyla that are, for many of them, entirely lacking segmented structures. One of the most impressive results coming from phylogenomics is undoubtedly the demise of the once strongly established "Articulata". From the strict point of view of parsimony, and looking only at the phylum level, it seems more reasonable to suggest that segmentation has been acquired at least three times independently in the three great branches of the bilaterian tree rather than considering multiple secondary losses of segmentation from segmented ancestors.

- So far, relatively few similarities have been found at the genetic level between segment formation processes in distant phyla, with two important exceptions: the existence of analogous "segmentation clocks" in short germ insects and vertebrates (Sarrazin et al., 2012) and the similar roles of Hedgehog signalling in segment polarity in arthropods and annelids (Dray et al., 2010). It can be argued that this relative paucity of evidence is partly a consequence of our ignorance. Segment formation processes at the genetic level are only well understood in one species, the fruit fly Drosophila melanogaster, thanks to the work of multiple groups starting with the pioneering work of Christiane Nüsslein-Volhard and Eric Wieschaus. However, it has been progressively recognized that the fruit fly "segmentation cascade", still academically taught as the central paradigm of segment formation, is in fact derived in evolutionary terms and even quite distant from the ancestral mechanisms in insects (Peel et al., 2005). The genetic processes of segment formation in the dorsal mesoderm of vertebrates, or somitogenesis, have been investigated by an increasing number of laboratories starting with the work of O. Pourquié's lab in the chick (Palmeirim et al., 1997). While the general principle of gene activity during somitogenesis (the "segmentation clock") has been uncovered (reviewed in Bénazéraf and Pourquié, 2013), it is still unclear how this segment formation clock is set in motion in early embryogenesis and how it is kept ticking regularly for the precise amount of time needed to make a strictly definite number of trunk and tail segments.

In this review, my goal is to illustrate why the study of annelid segmentformation is key to making progress on the crucial question of Urbilateria. Annelids are a key group of the third great branch of bilaterians, the trochozoans and the most understudied of the segmented phyla in terms of developmental biology. Annelids show a bewildering array of morphological, developmental and ecological diversity, that mirrors in many aspects the diversity of the arthropods. I will summarize the recent progress in reconstituting the phylogenetic tree of the annelids and I will describe how this improved phylogeny contributes to a much better understanding of how annelids evolved and diversified. I will explain in particular why teloblastic addition is a key aspect of segment formation and why, despite the variation it shows in distantly related annelid species, recent results help in reconstituting an ancestral scenario for posterior sequential addition in annelids.

\section{What is a segment?- annelid style}

The definition of segmentation is still a vexing problem. There is a great divide, to begin with, between those authors who view segmentation as a pattern and those who look at it primarily as an ontogenetic process, no matter what the morphological outcome is. The latter are mostly developmental biologists, especially those who have worked in recent years on the segmentation clock of vertebrates (for example, Richmond and Oates, 2012) but this developmental point of view has also some influence in other publications. To avoid any confusion, I call segmentation exclusively the anatomical repetition of parts, whereas I refer to their ontogenesis as "segment formation" (therefore I would rather use the term vertebrate "segment formation clock" when referring to vertebrate somitogenesis).

Even when speaking strictly of the anatomy, there are considerable misunderstandings between researchers as to which animals should be called segmented (Budd, 2001). As mentioned above, there is considerable variation, not only among metazoan phyla, but also within some phyla, in the structures and organs that show repeated patterns. This dispute has direct impact on the debate on the ancestry of segmentation. For some authors, segmentation is essentially limited to the three big phyla already mentioned above (chordates, annelids, arthropods), other phyla displaying repeated parts being either "pseudosegmented" (a vague term relating only to external annulation) or showing seriated organs. Mollusks are a key example. Some authors tend to see the old debate on whether mollusks are derived from a segmented ancestor as illegitimate because they view polyplacophorans and monoplacophorans essentially as unsegmented animals, that just display seriated organs (Wanninger and Haszprunar, 2002).

My personal bias is that a useful definition should be as inclusive as possible and free of influence from pre-existing opinions on the evolution of characters. I would therefore apply the word segmentation to any periodic repetition of anatomical units along the anterior/posterior axis. As suggested by Budd (2001), ani- 
mals cannot therefore be simply classified as segmented or not, they are more or less segmented. Animals classified by some as "pseudosegmented" or showing seriated organs have thus to be considered partially segmented. This pushes the boundary of segmentation well beyond the aforementioned "big three". This also leads to considering segmentation differently inside these "big three". As I will now explain, annelids comprise species that are among the most conspicuously segmented in the animal tree, but also species with no trace of segmentation at the adult stage. In this respect, annelids are even more diverse than arthropods. Recent progress in resolving the annelid phylogeny helps in determining an ancestral pattern of segmentation in annelids.

\section{The phylogenetic tree of annelids}

Annelids are a vast grouping of marine, freshwater and soildwelling animals. They comprise almost 20,000 species but this figure is probably a gross underestimate of the real diversity of the group. Groupings once recognized as cosmopolitan species are in fact complexes of several species (Méndez et al., 2000) and many species presumably remain to be discovered in the ocean depths (Osborn et al., 2009 for instance) or in the cold seas of the Antarctic.

Recent phylogenomic studies (Struck et al., 2011; Weigert et al., 2014) have confirmed many aspects that emerged earlier in more limited studies. The old classification of annelids in three groups ("Polychaetes", "Oligochaetes" and Achaetes) does not correspond to the current annelid phylogeny and should be considered obsolete. Instead, most annelids are found divided into two great branches, the Errantia and the Sedentaria, with a few more families emerging outside of this dichotomy. The leeches are nested into the "Oligochaetes" forming together the Clitellates, a large clade mostly of terrestrial and freshwater annelids. In turn, the
Clitellates are themselves nested inside the Sedentaria, indicating that they evolved from marine tubicolous ancestors. Echiuridae (spoon worms) and Sipunculidae (peanut worms), once considered separate animal phyla in their own right, are both nested within annelids. Pogonophorans and vent-worms, also once considered separate phyla, are now grouped in the family Siboglinidae and are related to the fan worms (Sabellida). Myzostomidae, a group of strange flatworm-like animals, commensal on echinoderms, are also emerging within annelids.

This tree still displays a number of uncertainties but it strongly supports one key idea: the last common ancestor of annelids was relatively complex in morphological terms, fully segmented, bore elaborate segmental appendages (parapodia) and had a distinct head with a range of sensory organs (Struck et al., 2011a; Struck, 2011b,).

\section{The segmentation of Errantians: close to an idealized defini- tion of metamerism}

Textbooks have classically taken earthworms (a group of large soil-dwelling clitellates that are the only annelids truly familiar to the general public) as a model for describing annelid morphology. The progress in clarifying annelid phylogeny suggests instead that the morphology of a number of Errantian families is much closer to the ancestral state in annelids. As a typical example, I will describe the morphology of Platynereis dumerilii, a species within the family Nereididae, that has emerged in recent years as a useful model for comparative developmental biology (Fischer and Dorresteijn, 2004).

No single animal is in fact better suited to describe a metameric arrangement than Platynereis. Most of the Platynereis body is formed of largely identical anatomical units (segments). In the

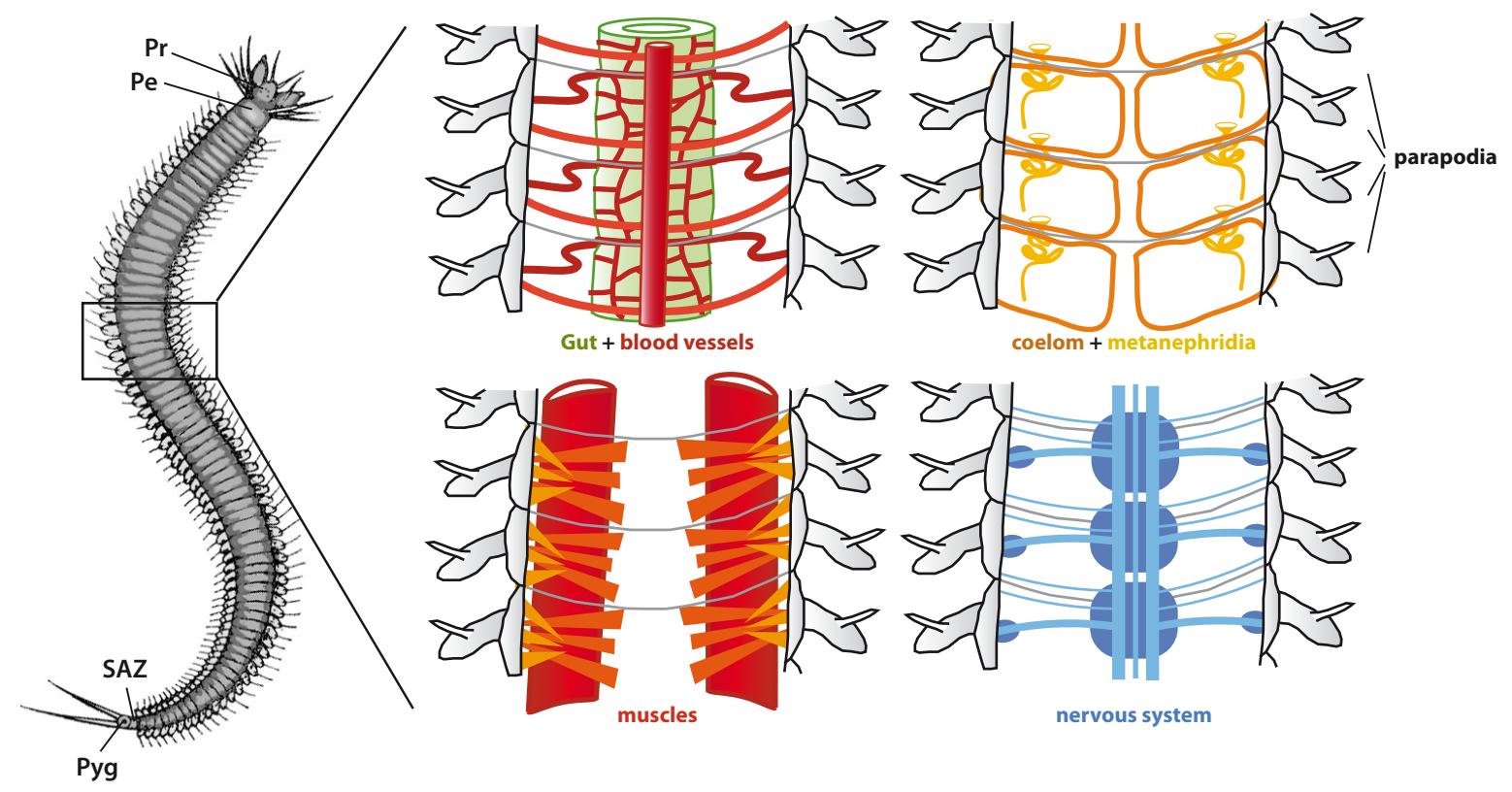

Fig. 1. The majority of marine annelids are completely metameric. This striking yet simple body organization is particularly obvious among juvenile and sub-adult Errantians. The drawing on the left represents a typical nereidid juvenile worm. The four sketches on the right illustrate in very simplified ways the repeated architectures of the different organ systems. In the "abdominal" segments of marine annelids, all organs follow this architectural rule. Only the gut and longitudinal muscles do not show a segmented structure when fully differentiated. It should be noticed that in contrast to many animals, most marine annelid species do not have a centralized gonad. Gametes mature inside the coelomic cavities. Abbreviations: Pr, protomium; Pe, peristomium; SAZ, segment addition zone; Pyg, pygidium. 

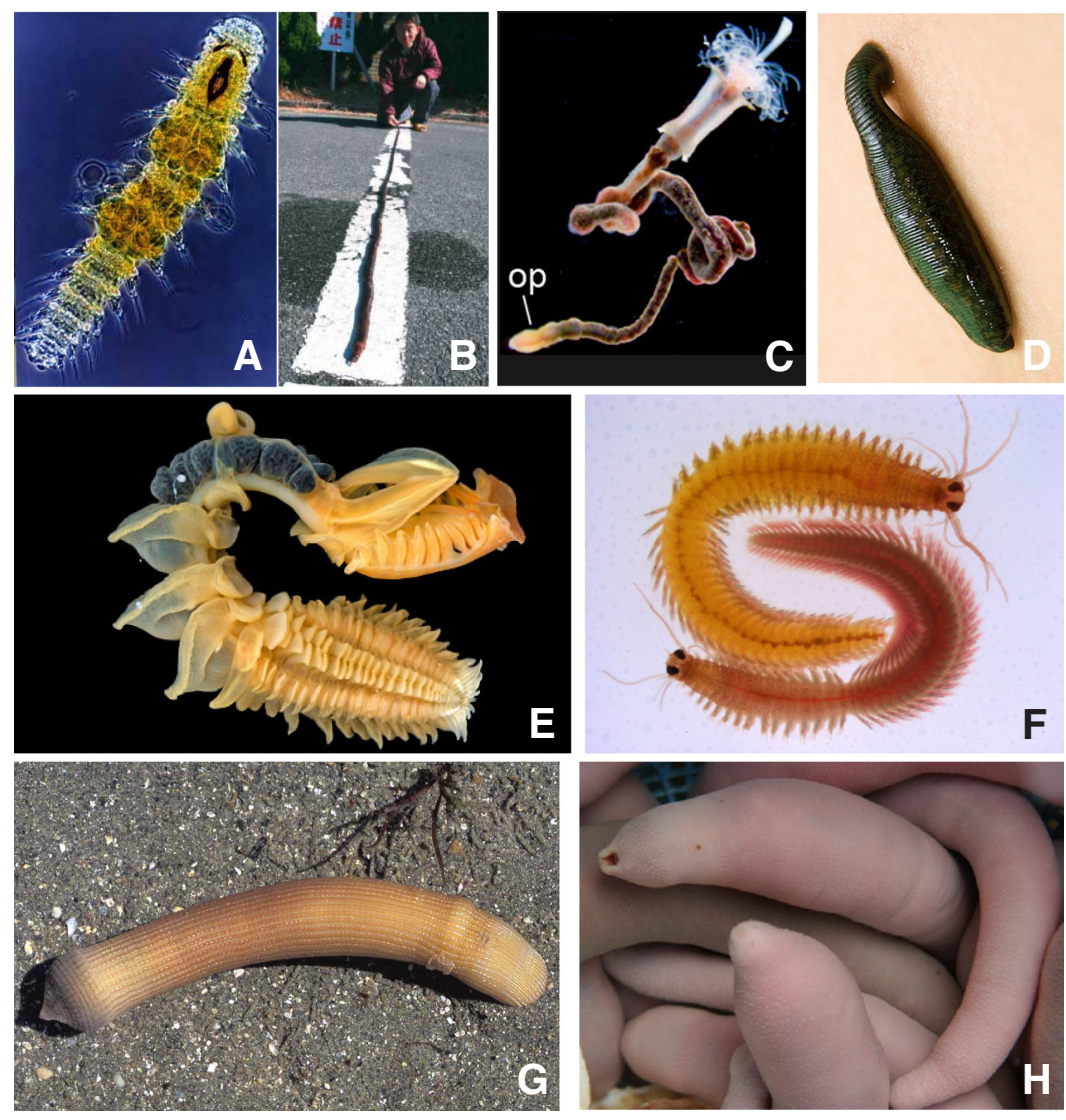

Fig. 2. Examples of diversification of the metameric body plan in annelids. (A) $A$ sexually mature Dorvilleid with 13 visible segments. (B) The longest eunicid ever found, a 3-meter long specimen of Eunice aphroditois counting 677 segments (Uchida et al., 2009). (C) The vent worm Lamellibrachia (Siboglinidae). In this species, only the short and stumpy posterior part of the body (op: opisthosoma) shows the typical annelid segmentation. (D) The medicinal leech Hirudo. Although the epidermis presents regular ring units (annuli), these do not correspond to internal segmentation. (E) Chaetopterus variopedatus is a tube-dwelling worm whose body is divided in three tagmata: a large head (fused with 9 segments), a thorax whose modified paddle-like parapodia help in creating a water current in the tube where the worm lives and an abdomen of indeterminate length where the gametes mature. (F) The sexually mature male and female swarming epitoks of Platynereis dumerilii. Each has a thorax lof 15 and 22 segments for male and females, respectively) and an abdomen of indeterminate length. (G) The Sipunculid Sipunculus nudus. (H) The Echiurid Urechis unicinctus. Photos courtesy of B. Paavo, K. Yamaguchi, G. Rouse, F. Pleijel and K. Tessmar-Raible.

sub-adult animal there are up to 80 segments. All organs respect the metameric patterns (Fig. 1). The only differences between segments in most of the body are relative to size: segments become smaller in the posterior part of the body, where they originate by budding. The only "non-segmental" parts of the worm body are the prostomium at the anterior tip and the pygidium at the posterior tip. The prostomium carries the brain and is rich in sensory organs and appendages. It is part of what is considered the "head" of the animal, together with a more posterior ring carrying the mouth. However, a large portion of this "head" actually derives from segmental units expressed during larval development. Only the brain, the mouth and a number of sensory organs (larval and adult eyes, antennae and palps) derive from a "non-segmental" unit of the larva, the episphere. The pygidium carries the anus and a pair of tentacular cirri. Segments that are located near the head show substantial variations, in the anatomy of the appendages (parapodia), in the organization of the circulatory, muscular and digestive systems.

This remarkably regular building of the body, very common in juvenile and sub-adult stages of both sedentarian and errantian families is called "homonomous" segmentation. Homonomy refers to the relative similarity of the segments along the anterior-posterior axis.

\section{How has segmentation diverged from ancestral homonomy in annelids?}

There has been considerable diversification of the ancestral homonomous body plan in annelids, resulting in a bewildering array of morphologies that in many ways compares with what is observed in arthropods. The morphological transformations can be classified in a number of categories:

- variation in the number of segments: in most annelid groups, segments are added posteriorly during the life time of the animal and most annelid species do not display a finite number of segments as most arthropods do. In consequence, there are considerable variations in the number of segments displayed at sexual maturity, even within a given group of annelids. For example, in the super-family Eunicida (Fig. 2), the number of segments varies from 12-15 in some minute Dorvilleidae species to several hundreds in some Eunicidae. Due to this variation, it is impossible to reconstitute an ancestral number of segments for a mature annelid. The annelid tree nevertheless tells us that the ancestral annelid had numerous segments added sequentially during its life cycle.

- tagmatization is the functional specialization of a group of contiguous segments. This is very common in annelids. Many annelid families have a group of anterior segments displaying a different shape compared to posterior ones and called "thorax" by analogy with insects and other arthropods. In the family Chaetopteridae, which potentially makes a basal branch in the annelid tree, the body is even divided in three units: "head" (prostomium + peristomium +9 anterior segments), "thorax" (5 segments) and "abdomen" (> 40 segments, indeterminate). Interestingly, in the family nereididae and in those species that reproduce by swarming (hence in Platynereis dumerilii), homonomy is lost and the division of the body in a thorax and an abdomen appears during the sexual metamorphosis (epitoky) at the end of the life cycle. The abdomen is more motile and helps in the rapid swimming of mature animals during swarming.

- partial loss of segmentation in some organs or tissues: examples are numerous. Uncharacteristically for annelids, leeches have a relatively small, finite number of segments. However, leeches do not have appendages and their epidermis often does not show clear separation between segments so that leeches do not look externally segmented (Fig. 2).

- complete loss of segmentation: siboglinidae, echiuridae and sipunculidae are particularly interesting because all three were once classified as separate phyla. In siboglinidae, most of the trunk of the 
animal shows no sign of segmentation. Only the posterior section of the body (opisthosoma) is made of segments. In Echiuridae and Sipunculidae, adult worms show no sign of segmentation, although in both groups, remnants of a segmented organisation are detected at the level of the nervous system during larval development (Hessling and Westheide, 2002; Wanninger et al., 2009).

\section{When and how are segments formed in annelid life histories?}

\section{Direct development, indirect development and in between}

Many marine annelids are classic examples of indirect development. Platynereis is again a good example of this type of development (Fig. 3, inspired from Fischer et al., 2010). After external fertilization in the water column, eggs release a jelly layer in which they develop. Embryogenesis gives rise in one day to an unsegmented swimming larva, called a trochophore. The trochophores free themselves from the jelly layer and swim into the water colum. In Platynereis, trochophores develop further without feeding (lecithotrophic development). After two days, the trochophore displays the first signs of a segmented organisation as ciliary belts present on each segment (paratrochs) start to appear. Inside the larva, ectodermal groups of cells invaginate to form the setal sacs responsible for the formation of the elaborate bristles (chaetae) borne by the segmental appendages (parapodia) so characteristic of annelids. Then the larva starts to elongate and clear separations start to appear between the three leg-bearing segments of the larva. At three days, the larva has taken the shape of a three-segment little worm. However, this is still a swimming pelagic larva called a nectochaete. This particular phase of development will last for several days during which the larva does not feed and does not make any other visible segment. Around ten days, the larva stops swimming, settles on the benthos and starts to feed. Segment formation then resumes from a posterior "segment addition zone" (SAZ), located immediately anterior to the pygidium. All the other segments will form by sequential budding from this SAZ. In Platynereis, similar to many other annelid families, this sequential production of segments will continue for most of the life of the animal.

At the other end of the spectrum, leeches develop directly
(Shankland and Savage, 1997). In most species, several eggs are laid together in a cocoon and the whole embryonic development takes place in the cocoon, without any intervening larval stage that resembles a trochophore. The embryo undergoes a highly stereotypical program of cleavage. Early on, two bilateral germ bands will start to form in an anterior to posterior direction, according to cellular processes that will be described in the next section. These germ bands fuse anteriorly to give the germ plate, from which originates most of the tissues of the embryo. This germ plate in turn starts to produce segmental units in an anterior to posterior progression, until the adult number of segments (32 in most species, fewer in some species) is formed. The young animal that hatches out of the cocoon therefore displays the complete adult body plan.

The types of development examplified by Platynereis on one side and leeches on the other side are thus divergent, especially with regard to segment formation. In Platynereis, embryogenesis produces an unsegmented larva. All the segments appear during post-embryonic development, either during larval development or for most of them during juvenile benthic development. On the contrary, in leeches, all adult segments are formed during embryonic development.

Which type of development is ancestral in annelids? To answer this question and to determine when segments were formed in the ancestral life cycle, I review the literature on those families whose phylogenetic position is well supported in recent studies (Struck et al., 2011). This work has no pretense of being the last word on the question because there are still a number of uncertainties in the phylogeny and some annelid families have yet to be analysed. Additionally complete descriptions of the developmental cycle are not yet available for all annelid families. Development has diversified considerably across the annelid tree. There are also abundant variations in some annelid families. There are terminological problems when dealing with annelid development. I defined three common life stages for the formation of segments: embryogenesis, larva and juvenile development, but there are discrepancies in defining the perimeters of each of these terms in annelids, depending on the annelid species considered and also on the authors. Part of this confusion is linked to the difficulties of defining precisely "direct" and "indirect" development in annelids because all sorts of intermediate situations exist among annelid species. In many

Fig. 3.The normal development of the nereidid Platynereis dumerilii. Segment formation is clearly segregated in two phases. The 3 anterior-most leg-bearing segments are formed more orless simultaneously starting 32 hours after fertilization. Notice that while the setal sacs component of the appendages of the three segments appear simultaneously, the paratrochs (ciliary belts born by each segment anlagen, in green)

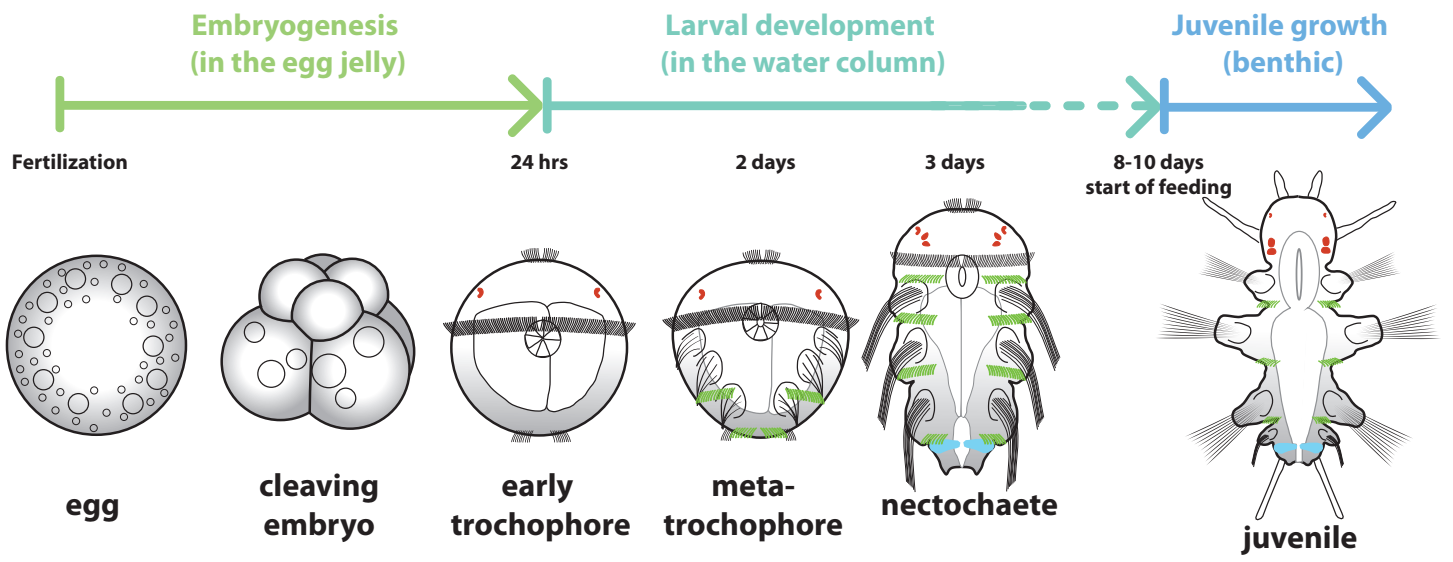
appear in an unusual poste-

rior to anterior succession. Once a three-segment nectochaete larval stage is reached in 3 days, a gap in segment formation happens that will last for several days while the larva is searching for a suitable place to settle in the benthos. It is only when the larva has stopped swimming and started feeding on the benthos that segment formation resumes by budding from a posterior, sub-terminal segment addition zone (SAZ, in light blue). 


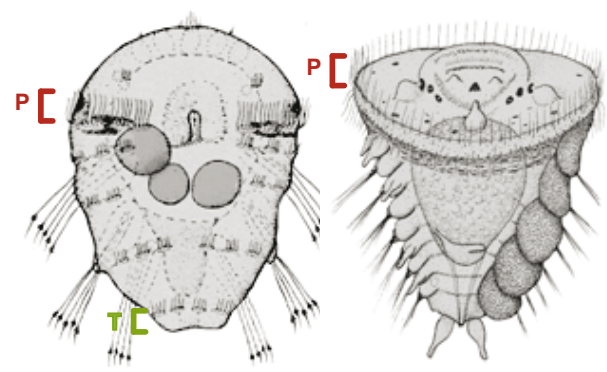

Platynereis bicanaliculata
Halosydna brevisetosa
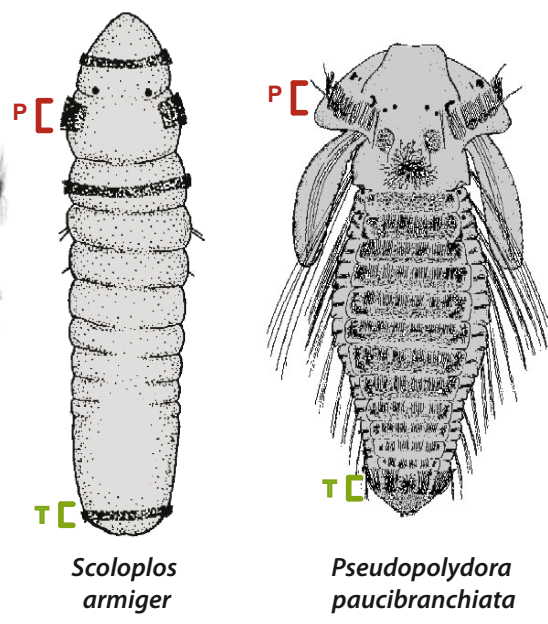

Pseudopolydora paucibranchiata
Fig. 4. Examples of the morphological variability before settlement in four annelid species. These larvae advanced metatrochophore stages and are close to becoming benthic juveniles. Variations are particularly visible at the level of the number of segment anlagen that have already been produced. These larvae however share a key characteristic, the prototroch (p). Many brooded larvae, which are kept in the mother's tube, such as in Scoloplos, keep a prototroch. Many trochophores and metatrochophores also have a telotroch (t). the telotroch is a ciliary belt borne by the pygidium and therefore always posterior to the SAZ. Pictures are adapted from Blake, 1975a; Anderson, 1959; Blake and Arnofski, 1999. species, instead of free spawning, as I have described for Platynereis, embryos or larvae are kept with the mother. They can be somehow attached externally to the tube or the body of the mother, or grouped within the tube of the mother (Wilson, 1991). In some cases, embryos even start to develop within the body of the mother and small worms are released through openings in the female body wall, especially in Syllidae. Many authors have called "direct" a development that involves brooding of the embryos/larvae with release of a benthic juvenile with no intercalation of a trochophore, metatrochophore or nectochaete swimming larva. The advanced developmental stages that are developing with the female, however, strongly resemble stages of pelagic larvae and are frequently motile due to the activity of their prototroch and other ciliary belts. These developments are therefore not direct in the sense that the stages retained with the mother, which are thus usually called embryos, are in fact comparable to the larvae of indirect developers. To classify segment formation relative to the developmental phases, I have thus used the following rules:

- in principle, embryonic development ends when a larva or a juvenile hatches from the egg shell. However, most annelids are peculiar in this respect. The eggs do have a "shell" that is actually an egg cuticle but the larva never truly hatches out of it. Instead, the egg cuticle is progressively incorporated into the cuticle that covers the tegument of the larva and later the young worm. When does embryogenesis end? A convenient substitute is to consider that it ends when the larva starts to swim freely out of the egg jelly. As for the species with brooding, embryogenesis ends when an unsegmented trochophore-like stage with a functional prototroch is reached, even if the larvae actually leave the mother later in development. This means essentially that among the non-Clitellate families, the vast majority of species do not make any segment during embryogenesis.

- What are the temporal boundaries of "larval" development. In Platynereis, the trochophore, metatrochophore and nectochaete stages up until the larva stops swimming and starts feeding encompass the larval development. In many annelid species with swimming larvae, the same stages apply. In those species in which larvae are brooded, I consider for the purpose of this analysis that larval development starts with trochophore-like stages. For similar reasons, this larval phase will come to an end whenever the feeding juvenile starts benthic life. How many segments are made during this phase? This is in fact highly variable (Fig. 5). Platynereis dumerilii and its three-segment nectochaete is not particularly representative of the marine annelids as in many species, many more segments are produced in swimming or brooded larvae. A few examples of this variability are illustrated in Fig. 4. In some Spionidae, up to fifty segments are present in a swimming larva. In Clitellates, this larval stage has completely disappeared.

- juvenile development starts with the benthic phase. In principle, this phase lasts until the animal reaches sexual maturity. In many swarming annelid species in which the animal undergoes a sexual metamorphosis (epitoky) and reproduces only once, the juvenile phase will indeed last for most of the benthic life of the worm. The vast majority of annelid species add segments sequentially from a persistent SAZ during juvenile development. Only a handful of species, including those of the family Pectinariidae (trumpet worms), have a full complement of segments when settling on the benthos. Most importantly, most Clitellate species that are not leeches do not hatch with a fixed number of segments and show posterior addition of segments during the rest of their life.

\section{The ancestral annelid life cycle: posterior addition of segments during both larval and juvenile development}

Examination of the tree in Fig. 5 allows a few important inferences about the last common ancestor of annelids:

- indirect development passing through a trochophore larva is ancestral. The nested position of clitellates within the Sedentaria leaves no doubt about the fact that their direct development is a derived trait. No segment was produced during the embryogenesis of this ancestral annelid.

- segments were made in two phases: larval and juvenile development.

- posterior addition of segments from a SAZ happened during both phases. There are relatively few groups where segments are formed simultaneously and in those groups in which this happens during larval development, it is clearly a derived feature. Thus the near simultaneous appearance of three segments described above in Platynereis is both uncommon and derived. So is the remarkable development of the chaetopterids where all segments in the two anterior most tagmata form simultaneously.

Due to the extreme variability even within families, it would be presumptuous to make a guess as to the number of segments that the ancestral annelid was sporting and also how many of these were 
formed during larval development. Again, the small three-segment benthic juvenile of Platynereis does not appear to be a particularly common situation in annelids and may be a derived feature. The ancestral annelid could have made many more segments during the pelagic larval life. Two more considerations could be brought into this problem. The first one is the old but still quite lively debate about the ancestral status of planktotrophy (Rouse, 2000 for a review). Many annelid species have pelagic larvae that feed on plankton and can remain pelagic for an extended period of time. There is no consensus on whether planktotrophy or lecithotrophy is the most ancestral in annelids and there are data to indicate that this larval characteristic has evolved in both directions. Theoretically, it is arguable that the longer time a larva will spend in the water column, the more segments it will be able to make. In reality, things are less simple. Some Spioniform species, for instance, brood lecithotrophic larvae that will make up to 21 segments before being released (Blake and Arnofsky, 1999).

Another type of argument comes from the expression of the famous "architect" Hox genes. Hox genes are typically expressed in bilaterian animals in "collinear" patterns along the anterior/posterior axis, i.e. their expressions are organized in overlapping domains in the same order as the genes are found in their chromosomal cluster. Hox expression profiles have been extensively studied in species with different modes of development: the closely related Nereidids Platynereis dumerilii and Alitta virens on one side and the Capitellid Capitella teleta on the other (Kulakova et al., 2007; Fröbius et al., 2008; Bakalenko et al., 2013). Capitella broods larvae that make thirteen segments before being released. Most of Capitella Hox

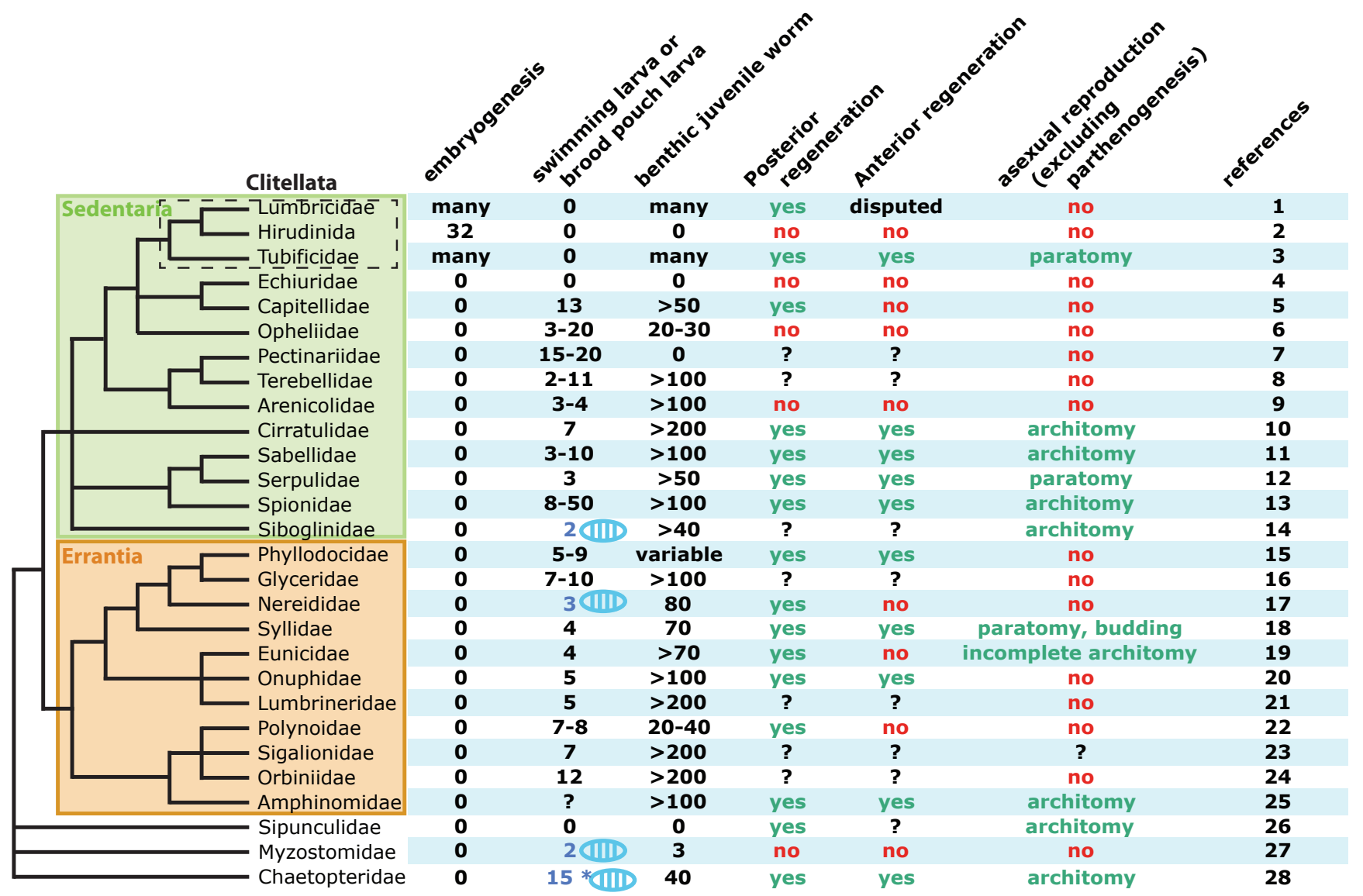

Fig. 5. Comparative table of the different modes of segment formation in the annelid tree. On the left is presented a consensus phylogeny of the majority of annelid species as suggested by recent works (Struck et al., 2011). The three first columns indicate the number of segments formed during the normal development of the studied species. The three following columns indicate the absence or presence of segment formation during three other processes, anterior and posterior regeneration and asexual reproduction by fission. This table is neither exhaustive nor definitive but it has the goal of illustrating the ample variations that annelid species have evolved and the difficulty of reconstituting the development and life history features of the last common ancestor. Few annelid species have been documented in each family. It is thus highly likely that additional variability exists within families. The striped embryo indicates families in which the documented species form all larval segments simultaneously. In all other families, a few anterior-most segments can appear simultaneously but there is evidence of posterior addition for more posterior segments. The asterisk in the Chaetopteridae larva column denotes the formation of the three tagmata prior to their subdivision in segments. References are: 1; Gates, $1949,1950$. 2; Shankland and Savage, 1997. 3; Nakamoto et al., 2000; Bouché et al., 2005. 4; Hessling and Westheide, 2002. 5; Giani et al., 2011. 6; Bely, 2005. 7; Wilson, 1936. 8; McHugh, 1993. 9; Farke and Berghuis, 1979. 10; Blake, 1975a; Gibson and Clark, 1976. 11; Rouse and Gambi, 1998; Giangrande et al., 2000; Kolbasova et al., 2013. 12; Kupriyanova et al., 2001; Pernet, 2001; Nishi and Nishihira, 1994. 13; Blake and Arnofsky, 1999; Gibson and Harvey, 2000. 14; Southward, 1999. 15; Blake, 1975b. 16; Crumrine, 2001. 17; Fischer et al., 2010. 18; Allen, 1964. 19; Richards, 1967; Akesson, 1968. 20; Allen, 1959; Pires et al., 2012. 21; Cazaux, 1970. 22; Bhaud and Cazaux, 1987; Blake, 1975a. 23; Blake, 1975a. 24; Anderson, 1959; Blake, 1980. 25; Kudenov, 1974. 26; Rice, 1970. 27; Eeckhaut, 2003. 28; Irvine, 1999. 
genes are expressed in collinear patterns in a late metatrochophore larva. By contrast, in Platynereis and Alitta, collinearity is less clear and only anterior Hox genes are expressed in the three segments of the larva. Interestingly, Bakalenko et al., (2013) found a much more regular collinear expression of Hox genes in a more advanced developmental stage of $A$. virens, a 15-segment juvenile. One could argue therefore that this juvenile stage of $A$. virens is the temporal homologue of the late Capitella metatrochophore and that the derived expression of Hox genes in the three-segment, early-settling larva of nereidids is an indication that this larva is itself a derived characteristic within annelids. More investigations would be needed however to test the value of this argument.

\section{Regeneration of segments: two distinct pathways}

Regeneration of amputated body sections is very widespread in annelids (Fig. 5). Posterior or "caudal" regeneration after the amputation of the posterior part of the worm is almost universal among annelids. Only a handful of groups do not display this capability. Given their scattered position within the annelid tree, it seems highly likely that the ancestral annelid displayed a posterior regeneration capability that was only lost in a handful of derived lineages. Anterior regeneration is also widespread but it is absent in a much larger proportion of groups (including for example all Nereidids). There are however good arguments in favour of its ancestral status (Bely, 2006). The processes for the regeneration of segments seems however quite different between posterior and anterior regeneration. During posterior regeneration, which has been well studied in a large number of annelid species (Müller 2004, Giani et al., 2011; Pfeifer et al., 2012 for recent studies), the first event is the formation of a regeneration blastema. This blastema rapidly regenerates a new terminal piece, the pygidium, with a functional anus. Then sequential addition of segments resumes in a manner that looks very similar to normal growth (Gazave et al., 2013). This suggests that a new SAZ has been regenerated and this $S A Z$, as we will see in the next section, contains regenerated teloblasts. During anterior regeneration, no process of sequential addition is detectable. Typically, in addition to the prostomium, a fixed number of segments are regenerated ("head segments" in clitellates) but these segments all differentiate more or less at the same time. For example, in Enchytraeus japonicus, where asexual reproduction by fission occurs in addition to anterior and posterior regeneration, a prostomium plus seven head segments are regenerated when the worm is amputated of more than seven anterior segments (Myohara, 2012). By contrast, if the worm is amputated within the "head region", i.e. in segments between 1 and 7 , the anterior blastema will regenerate just as many segments as necessary to complete the number of head segments to seven. Such observations suggest that different programs are at work in anterior and posterior regeneration, which is in fact correlated to the fact that anterior and posterior regeneration have evolved divergently to some extent in the annelid tree (Fig. 6).

Segments are formed during another important aspect of life history in a number of annelid species: asexual reproduction by fission. Architomy is the most common process used: the worm undergoes transversal fissions producing a number of fragments. Each of these fragments will regenerate the body parts that are missing, either a "head" (prostomium + a few segments), or a "tail" (pygidium + new SAZ) or both Gibson and Harvey, 2000, Kolbasova et al., 2013 for detailed descriptions in Spionidae and Sabellidae). In a number of families (many clitellates, serpulids, syllids), another fission pathway called paratomy happens. In paratomy, one or several "fission" zones
A. Juvenile posterior elongation
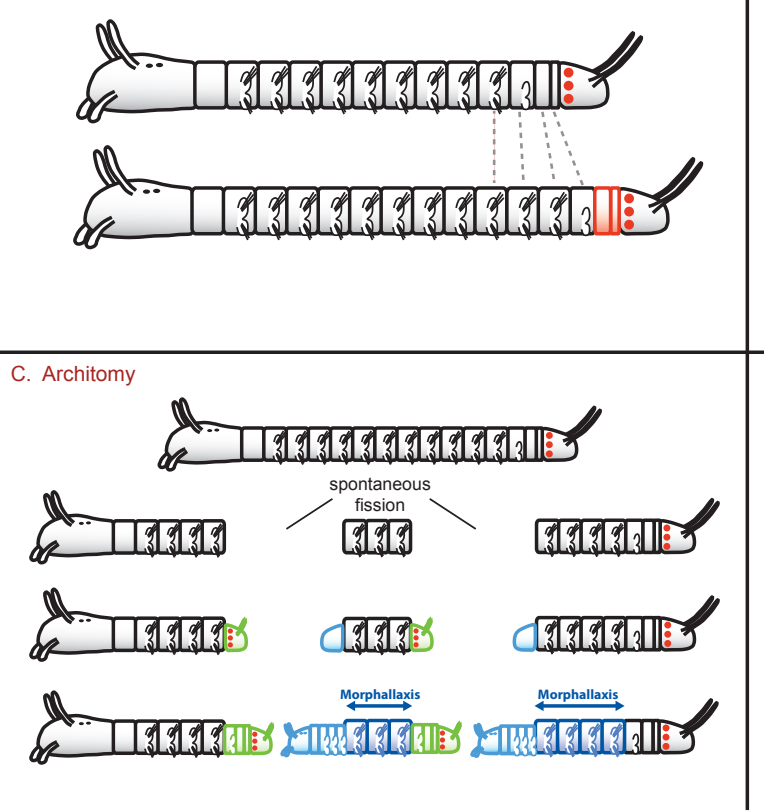

B. Anterior and posterior regeneration
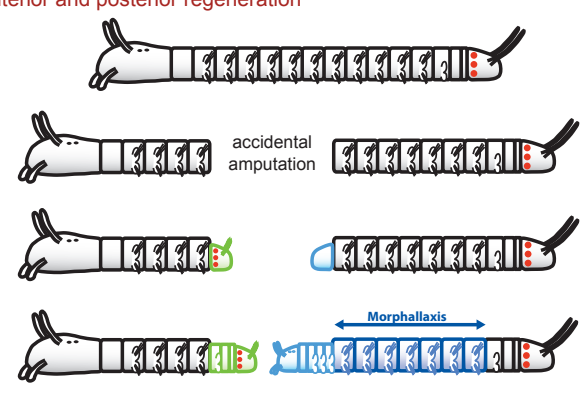

D. Paratomy
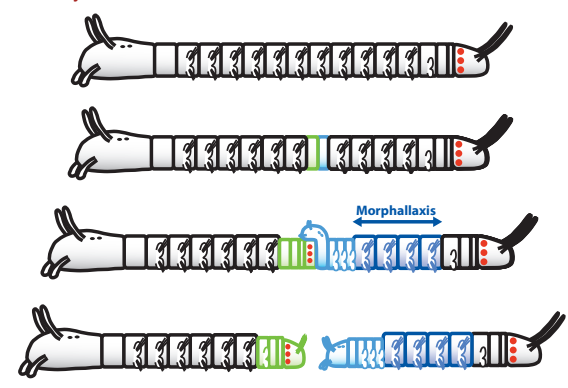

Fig. 6. A comparison of the segment formation processes in annelids. Segments are made during normal benthic development, regeneration and asexual reproduction processes, in the species in which these developmental modes are present. A key similarity between normal posterior growth, posterior regeneration and formation of a posterior part during asexual reproduction is the activity of the teloblasts (schematized by red dots). (A) Teloblasts divide asymmetrically to give the precursors of segment anlagen (in red). (B) After caudal amputation, teloblasts are regenerated from an unknown source and resume their work to produce all posterior segments. (C) During architomic reproduction, the same process is at play: new teloblasts appear near the fission place. (D) During paratomic fission, this process is accelerated and segment production starts before fission. The sequential addition characteristic of teloblastic activity is however preserved, suggesting that new teloblasts are formed before the fission event. Anterior regeneration, both accidental or in asexual reproduction seems to follow a largely different course, as a small and fixed number of segments are formed more or less simultaneously, irrespective of the number of segments initially missing. This suggests that entirely different processes of segment formation are involved with no equivalent of the posterior teloblasts. 
appear along the trunk of the worm. In each of these fission zones, a new "head" and a new "tail" start to differentiate but stay attached to one another as differentiation and growth proceeds. Eventually, the fission takes place between the new tail and the new head of the contiguousclonal individuals produced (Pernet, 2001 for a description in Serpulidae). The process of paratomy is pushed to remarkable extremes in the family Syllidae (Franke, 1999). Some syllids produce a multiplicity of clonal individuals through stolonization: stolons do not feed and are entirely specialized for sexual reproduction in a brief period of swarming (epitoky).

There is a strong link between the existence of asexual reproduction and the capability for regeneration in annelid species. As the table of Fig. 5 shows, the groups where asexual reproduction happens display both anterior and posterior regeneration. In fact, reformation of a "head" and "tail" during both architomy and paratomy strongly resemble regenerative events. As in post-amputation regeneration, reformation of a "tail" entails regenerating a pygidium and a functioning SAZ. Reformation of a "head" entails regenerating the prostomium and a fixed number of anterior segments (Zattara and Bely, 2011). There are thus again two different pathways for segment formation, similar to post-amputation regeneration. Bely (1999) and earlier authors have proposed that the similarities between regeneration and asexual reproduction can be explained by the fact that asexual reproduction by fission in annelids (and maybe other groups) is evolutionarily derived from regeneration. Given this scenario, it is in principle conceivable that asexual reproduction may have been present in the last common ancestor of annelids itself if we admit that both anterior and posterior regeneration were also present. The presence of fission is however relatively sparse among annelid families and it is also perfectly conceivable that it evolved several times independently within annelids in fully regenerating lineages.

\section{Posterior segment formation at the cellular level: teloblasts}

\section{A module by module approach for the comparison of segment formation processes}

The comparison of the cellular and genetic mechanisms of segment formation at large evolutionary scales poses a number of challenges. For more than two decades, the genetic segmentation cascade of the fruit fly has been the central paradigm for segment formation in animals. Then increasing knowledge of somitogenesis mechanisms in vertebrates has shown that segments could be formed in very different ways in distant lineages: not the same cells, not the same genes and not the same processes. Increasing knowledge of segment formation in arthropods other than the fruit fly has revealed a complex mix of similarities and divergences (Peel et al., 2005; Damen, 2007). The complexity of these comparisons requires a framework for analysing segment formation that is not based solely on the divergent fruit fly model but is capable of taking into account the vast diversity of bilaterian animals.

I will briefly introduce such a framework in this part although a full discussion of it will be proposed in another article. The process of segment formation is basically segmented in three developmental modules that could be overlapping in space but not time (simultaneous segment formation as in fly), or in time but not space (activity of a sequential SAZ). Module 1 is the production of an elongated anterior-posterior axis. Module 2 is the specification of segmental periodicity (the true "making" of segments). Module 3 is the anterior/posterior patterning of individual segments, once they have been defined and delimitated by module 2 .

As an example, the segment formation processes of three key animal models, the fruit fly, vertebrates and Platynereis, have been divided according to this categorization in Fig. 7. Such a categorization allows not only the comparison over a large phylogenetic scale, but also in cases when segment formation happens at different times in life history. This is clearly the case within annelids when leeches are forming segments during embryogenesis and non-clitellates are forming all segments after embryogenesis. This framework can also be used to compare different pathways for segment formation in different times of life history in the same species. For instance, one can compare segment formation between larval and juvenile development or between normal development and regenerative development. In the rest of this article, I will apply this framework to the study of posterior sequential addition across annelids.

\section{The teloblasts of clitellates}

Teloblasts have been extensively studied and characterized
Production of an elongated A-P axis
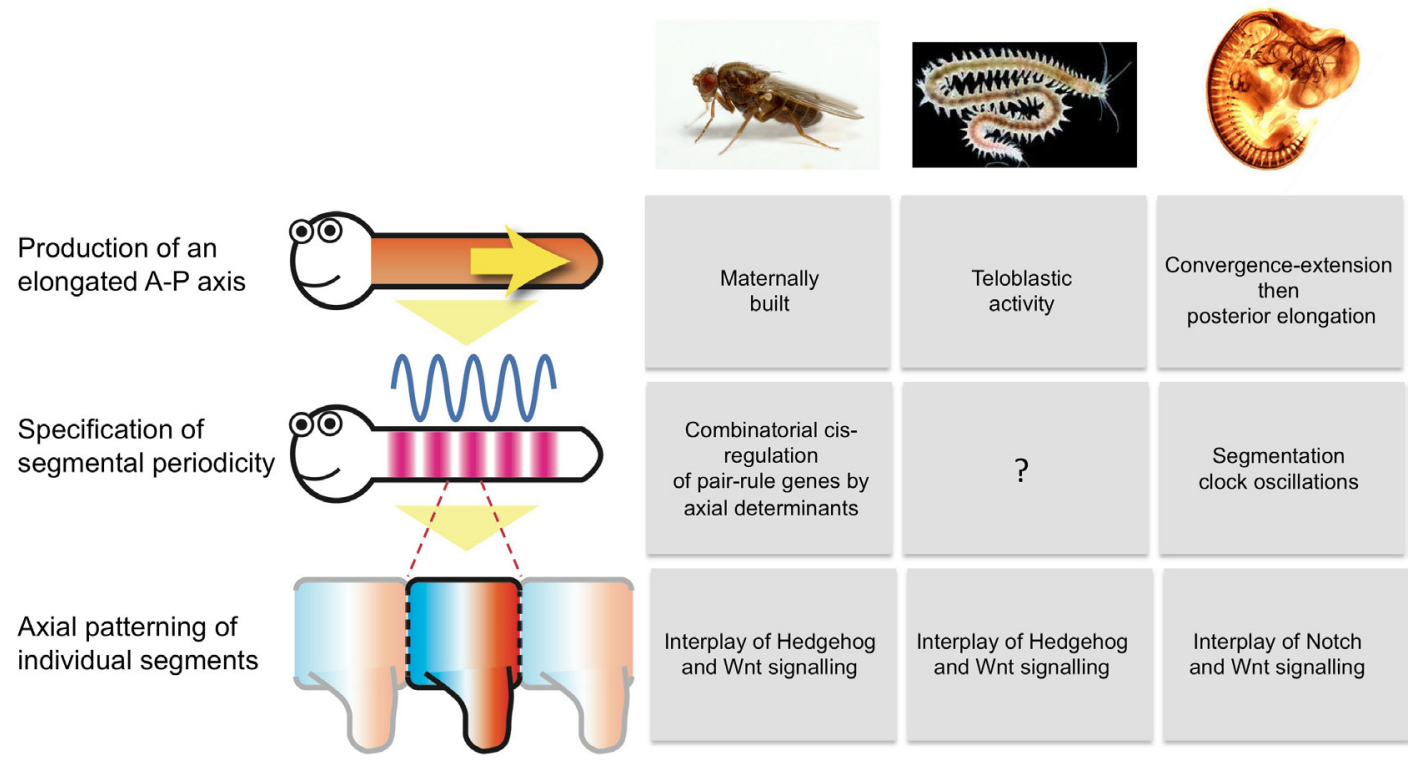

Fig. 7. A comparative modular approach of segment formation processes at the cellular and genetic levels. Three model organisms taken from the three superclades of the bilaterian tree are analysed correspondingly. Generally speaking, these animals do not make their segments in the same way. However, the patterning of segment polarity in Annelids and Arthropods involves two crucial signalling pathways, hedgehog and Wnt/B-catenin, in the same spatial relationship (Dray et al., 2010). 
in leeches, to a large extent through the impressive work over four decades of the group of David Weisblat at the University of California, Berkeley. Leeches, as described above, have a direct form of development. This type of development has already been described in multiple works and reviews (Shankland, 1991; Shankland and Savage, 1997; Lang and Shain, 2009 for instance) and I will here only describe the major elements (Fig. $8 \mathrm{~A}$ ). The cleavage of the egg follows the determinate "spiral" pattern that is widespread in Spiralians. This cleavage is very unequal in the leech. The first two cleavages segregate a large proportion of the cytoplasmic material of the egg within a single blastomere, D, that will subsequently give rise to the vast majority of the trunk tissues of the embryo. This $D$ blastomere also inherits a specialized part of the cytoplasm, depleted in yolk but rich in organelles and RNA, the teloplasm. Dividing further, the D blastomere gives two bilateral pairs of mesodermal (M) and ectodermal precursors (NOPQ). The ectodermal precursors NOPQ divide to give the four bilateral pairs of ectodermal teloblasts $\mathrm{N}, \mathrm{O}, \mathrm{P}$ and $\mathrm{Q}$. Together with the $\mathrm{M}$ teloblast, there are thus five pairs of teloblasts sitting at the posterior pole of the embryo, together with the descendants of the micromeres. The teloblasts are very large and conspicuous cells in the leech embryo. Each of the teloblasts, both ectodermal and mesodermal, undergoes a series of highly asymmetric divisions, producing a continuous and regular chain of segmental precursors, called a germinal bandlet of primary blast cells (PBC). $\mathrm{M}, \mathrm{O}$ and $\mathrm{P}$ produce one $\mathrm{PBC}$ per segment whereas $\mathrm{N}$ and $\mathrm{Q}$ produce two PBCs per segment. Each hemisegment will therefore originate from the mitoses of seven PBCs (2n, 1o, 1p, 2q, 1m). Germinal bandlets, initially disjointed, fuse to form two bilateral germinal bands. Germinal bands will ultimately differentiate in all the tissues of the leech trunk. In each of the bandlets, each primary blast cell undergoes a constant stereotypical program of mitoses and will give rise to a constant subset of segmental cells according to their teloblast of origin (mesoderm for $\mathrm{M}$, predominantly neural tissues for $\mathrm{N}$ and $\mathrm{O}$, predominantly body wall epidermis for $\mathrm{P}$ and $\mathrm{Q}$ ).

The dominant characteristic of leech development is therefore an entirely determinate fixed-lineage program. Teloblasts produce a fixed number of segmental precursors and are progressively "consumed" as they divide further. The anterior/posterior axis elongation (module 1 ) is thus entirely linked to the activity of teloblasts. Moreover, the segmental periodicity (module 2) is determined by the mitotic programs of the teloblasts. Lastly, the segment polarity (module 3 ) is already determined itself when the very first divisions of the PBCs are taking place because the daughter cells of the PBCs make entirely stereotyped contributions to the segment along the anterior/posterior axis. The entire program for determining a segmented organisation of the trunk is run during the teloblast divisions and the very first PBC divisions, producing cells that are already committed for a specific fate in a given segment. Segment boundaries make their first physical appearance (especially obvious at the level of the ventral nerve chain) only much later in development.

Teloblasts, in a restricted definition, are thus small sets of progenitor cells clearly identifiable by their size and position in the embryo, that divide asymmetrically to generate the various tissues of the trunk. Their lineage of origin is completely determined. Leech teloblasts are not stem cells, strictly speaking, as their maintenance is not indeterminate. They are limited to embryogenesis and no segment is produced after hatching of a juvenile with a full comple- ment of segments (usually 32).

Teloblasts very similar to the leech are found in non-leech clitellates (Tubifex for instance, Goto et al., 1999, Nakamoto et al., 2000). Non-leech clitellates however do not have a determinate number of segments and segments are sequentially added after embryogenesis during juvenile development and also during posterior regeneration. This post-embryonic segment addition takes place in the absence of readily visible teloblasts (i.e. big cells) at the posterior tip of the trunk. This shows that even in clitellates, different mechanisms are sequentially used for the normal production of segments.

\section{The teloblasts of non-clitellate annelids are a new category of stem cells}

Non-leech clitellates thus resemble the general situation of posterior segment addition in most non-clitellate annelid families, be it during larval or juvenile development. There are no conspicuous posterior cells playing the same role as the leech teloblasts in these groups. This situation can have two explanations:

- Teloblasts in these groups are small cells, not very different in size from the surrounding cells. the SAZ is thus made of inconspicuous teloblast-like cells. They would behave in some aspects like the leech cells, in particular, they would divide asymmetrically to give committed segment precursors.

- Teloblasts truly do not exist. The SAZ is a zone of "diffuse" cell divisions. Cells divide symmetrically, with no privileged orientation and no distinction exists among cells that are "naïve" precursors and cells that are committed to a segmental fate. Segmentation is induced at the anterior boundary of this elongating SAZ by the neighbouring tissues. This is seemingly how somitogenesis proceeds in vertebrates. The presomitic mesoderm is the posterior paraxial unsegmented tissue that buds off new somites at its anterior end, and the examination of the mitotic activity of cells in the PSM reveals unoriented divisions (Bénazéraf and Pourquié, 2013).

Very few data were available until recently to support one model or the other in marine annelids. Anderson (1959) described the teloblasts of the Orbiniid Scoloplos armiger, based on sectioned tissues, without experimental evidence.

Results obtained in Platynereis clearly support the first scenario (de Rosa et al., 2005; Gazave et al., 2013). Remarkably, these experimental results were obtained whilst comparing two phases of segment formation: normal posterior addition (in fact, the formation of the fourth legged segment in the juvenile) and the posterior addition after caudal regeneration. The mechanisms were essentially similar. Two separate ring-shaped populations of cells were located by using a number of molecular markers just anterior to the pygidium of Platynereis (Fig. 8B):

- an external ring of ectodermal cells embedded in the surrounding epidermal cells. This ring is only 1-2 cells wide in anterior/ posterior extension (Fig. 8C). It is inserted in between the cells of the pygidium that have a low mitotic activity. EdU labellings show that these cells are undergoing coordinate waves of mitoses (de Rosa et al., 2005; Gazave et al., 2013). The exact orientation of cell divisions has however not yet been observed. The cells are not present in a distinct number and they are not organized in a perfectly aligned arrangement. These cells are characterized by a very specific molecular signature including transcription factors evx, $c d x, H o x 3$ and AP2. Their divisions give rise to all ectodermal derivatives of the trunk (epidermal and neural tissues notably). 
- an internal ring of mesodermal cells. These cells are lying immediately beneath the ring of ectoteloblasts. They are also in contact with a large circular blood lacuna located between the midgut and the hindgut. EdU labellings reveal ample mitotic activity of these cells but no obvious coordination between neighbouring cells. Mesodermal precursor cells display a specific molecular signature including transcription factors Runx and hunchback.

Both populations display cells with the cytological characteristics of stem cells, i.e. a high nucleo-cytoplasmic ratio. However the sizes of these cells are not considerably different from the neighbouring non-stem cells. Most importantly, these ectodermal and mesodermal precursor cells share an elaborate molecular signature with the germinal stem cells of Platynereis (Rebscher et al., 2007, Gazave et al., 2013). This includes a number of well known conserved markers of the metazoan germ line such as the RNA-binding proteins Piwi, Vasa or Nanos. These molecules are thus presumably part of an ancestral "stemness" program that is shared by some but not all metazoan types of stem cells. Other crucial examples of stem cells sharing this program are the neoblasts of planarians and the interstitial cells of cnidarians (Juliano et al., 2010). The "stemness" program remains expressed for a more or less extended period of time in cells that are already segregated to segment anlagen. These cells, located in differentiating segments, are presumably already committed to a segmental fate but are still undifferentiated.

\section{A new comprehensive definition of annelid teloblasts}

Gazave and coauthors propose that these posterior stem cells are at the origin of all the segmental tissues of Platynereis and are behaving like teloblasts. These cells however display important differences with the leech teloblasts. They are true stem cells, present during most of the life cycle of the animal, sitting in a niche near the pygidium, where they are constantly supplied with nutrients by the general blood circulation. Given their small size, it is difficult to carry out the sort of dye injection experiments that have been performed on the leech teloblasts to analyse the progeny of Platynereis teloblasts. Cytological characteristics suggest that these cells divide asymmetrically but the divisions of these cells have not been observed directly so far.

The teloblast-like cells of Platynereis are responsible for the elongation of the anterior-posterior axis (module 1). Much work needs to be done to understand how they would contribute in segment periodicity (module 2 ) and segment polarity (module 3 ). The coordinate mitoses observed in the ectoteloblasts of Platynereis may suggest that, as in leech, the cell cycle of teloblasts could be completely correlated with the determination of segment boundaries. It is conceivable that each cycle of ectoteloblast divisions produces a ring of segmental precursors that are already entirely
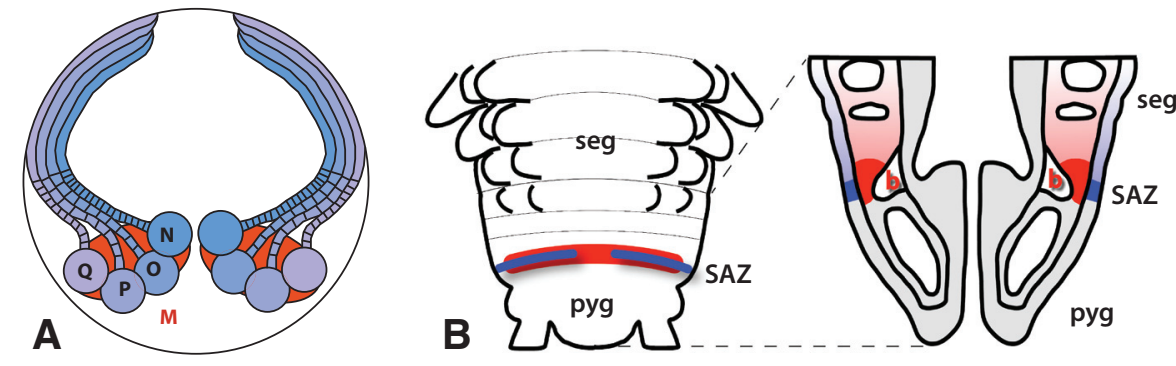

Fig. 8. Teloblasts in leech and Platynereis. (A) During leech embryogenesis, the teloblasts are large conspicuous cells provided with the cytoplasmic material necessary to build the entire embryo germ band. There are four pairs of ectodermal teloblasts (in shades of blue) and one pair of mesodermal teloblasts (red). Teloblasts divide in a coordinate way to produce bandlets of segmental precursor cells. These precursor cells will themselves divide in stereotyped ways to give segmental tissues. (B) Ventral schematic view of posterior segment addition in Platynereis. Teloblasts are relatively inconspicuous cells located in two rings, one ectodermal (blue) and one mesodermal (red) just anterior to the pygidium. These two rings together form the SAZ. Being active during most of the life of the animal, teloblasts have the characteristics of adult multipotent stem cells, i.e. capable of giving precursors of most tissues and capable of self-maintenance and self-renewal through cell divisions. They are constantly supplied in nutrients by a large circular blood vessel in their vicinity. (C) EdU labelling shows their coordinate mitotic activity by contrast with the scattered mitoses occuring in segmentanlagen. (D) Close up view of the ectodermal SAZ showing the large nuclei and the expression of Piwi, characteristic of stem cells. On the right are listed a number of RNA binding proteins and transcription factors that are part of the specific molecular signature E pyg

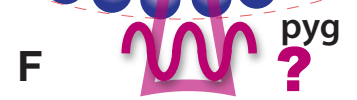

of the ectoteloblasts. (E,F) Two scenarios for the role of ectodermal teloblasts in Platynereis. In (E), the teloblasts mitoses, as in the leech, are driven by an internal autonomous oscillator that define the segmental periodicity. Anterior daughter cells are already committed to a given segment. In (F), the cyclical activity of the teloblasts has no connection with the segmental periodicity which is determined by an oscillator located in neighbouring tissues. 
committed to giving the whole ectoderm of a single segment (Fig. $8 \mathrm{E})$. Alternatively, teloblast divisions may produce uncommitted cells and segment periodicity would be imposed on these cells by periodic inductive signals emanating from the neighbouring tissues (Fig. 8F)

Is it likely that the teloblasts of leeches and the teloblasts of Platynereis might be homologous cell types? Part of the answer to this question depends on how widespread the posterior stem cells described for Platynereis will eventually be found among annelids. The Platynereis teloblasts correspond well with the ectoteloblasts and mesoteloblasts described by Anderson in Scoloplos, a distantly related species of marine annelid (Orbiniidae). In Capitella (Capitellidae), the only other species of marine annelid in which extensive studies of the larval and juvenile development have been conducted, Seaver et al. (2005) did not detect profiles of coordinated mitoses at the posterior end of the trunk that would be reminiscent of the Platynereis teloblasts. However, a number of Capitella genes show expression patterns towards the end of the larval development very similar to the SAZ expressions described for Platynereis. In particular, evx and Hox3 are expressed in ringshaped patterns at the location of the ectodermal SAZ (Seaver et al., 2012; Fröbius et al., 2008), runx is expressed in a ring-shaped pattern in the mesodermal SAZ (Seaver et al., 2012) and the RNAbinding protein coding genes vasa, nanos (Dill and Seaver, 2008) and piwi (Giani et al., 2011) are expressed in both cell populations of the SAZ. This suggests that a SAZ very similar to Platynereis is present in Capitella and presumably homologous teloblasts have yet to be fully characterized.

How can we conceive a scenario for the evolution of the teloblastic SAZ in annelids? The overall similarity of posterior segment addition in larval and juvenile development and the molecular similarities found between the distantly related Capitella (Sedentaria) and Platynereis (Errantia) suggest strongly that a teloblastic SAZ with small teloblasts was present in the ancestral annelid. How then could the clitellate big teloblasts have evolved from these ancestral small teloblasts? The major difficulty resides in the fact that the big teloblasts in leech and earthworm are embryonic features, whereas small teloblasts are larval and juvenile features. A crucial evolutionary process may explain this discrepancy: heterochrony. In clitellates, segment formation has been considerably accelerated so that a large proportion (non-leech clitellates) or all of segment formation (leech) takes place in the embryo, coincident with the complete loss of the larval stages. Teloblasts of the early clitellates now had to carry out the work of producing up to several dozen segments in the reduced time span of embryogenesis. The characteristics of the ancestral small, self-renewing, teloblasts thus disappeared as they evolved into the large expendable embryonic teloblasts of clitellates.

One important piece of evidence that could be brought in favour of such a scenario would be to trace the lineages of the small teloblasts of non-clitellate annelids back in the embryo and compare it to the lineages of clitellate teloblasts. This has not been resolved unambiguously in Platynereis to date. Lineage tracings of blastomere fates with dil in cleavage-stage embryos of Platynereis have been carried out up to three days of development (Ackermann et al., 2005). Injection of the 4d blastomere, which belongs to a homologous lineage to the leech DM blastomere labels the whole trunk mesoderm of the larva but more heavily labels a small group of cells located internally just in front of the forming pygidium. These cells express the gene vasa (Rebscher et al., 2007) and comprise the primordial germ cells of the worm as well as the precursors of the mesodermal teloblasts. Fischer and Arendt (2013) have determined that the embryonic precursors to the mesodermal teloblasts undergo a series of stereotyped asymmetric cell divisions to produce first the primordial germ cells and subsequently the precursor cells of the mesoderm of the 3-segment larva in the same way as the leech M teloblasts. The injection of the $2 \mathrm{~d}$ lineage, homologous to the DNOPQ lineage of the leech has not been carried out to date in Platynereis. dil injection of 20 in Capitella (Meyer and Seaver, 2010) however labels heavily a thin ring of cells immediately in front of the pygidium in the late larva, that presumably corresponds to the ectodermal teloblasts.

There is thus convincing evidence that the small teloblasts of non-clitellate annelids are homologous to the big teloblasts of clitellates and should be consolidated into a common definition based on their most common appearance and function in annelid families. My proposal is that teloblasts are posterior progenitor cells that divide asymmetrically to give birth to the ectodermal and mesodermal precursors of segments. Ectoteloblasts and Mesoteloblasts derive from separate embryonic stereotyped lineages but proliferate to give ring shaped populations anterior to the pygidium. These two rings of cells constitute the SAZ of the worm. Non-leech clitellates will be interesting to investigate in the future as they represent an intermediate situation between non-clitellates and leeches. In juvenile non-leech clitellates, typical posterior addition, as seen in non-clitellates, comes after the fixed lineage embryogenesis similar to leech.

\section{Teloblasts can be regenerated}

As shown in the study of Platynereis posterior growth, a proper SAZ with its two rings of teloblast cells is regenerated very rapidly after caudal amputation. As the original teloblast cells of the worm have been removed by the amputation, the new teloblasts must have been regenerated from unknown pools of cells residing in the neighbouring uncut segments of the worm. In the clitellate Enchytraeus japonicus, it has been suggested that all trunk segments present specific stem cells called neoblasts, distributed regularly and at specific locations (Sugio et al., 2012). Their dynamics have been studied during the events of regeneration that follows fragmentation in the process of asexual reproduction. When the fragmentation occurs, these cells start to proliferate and to migrate towards the location of the wound. They participate to the formation of a regeneration blastema, producing the mesodermal component of the blastema. There is also a suggested contribution of epidermal tissues in the immediate vicinity of the fragmentation site to the formation of the blastema.

Neoblasts cells have so far not been observed outside of clitellates. If they do generally exist in annelids, it will have to be investigated whether they are capable of regenerating the teloblasts, at least the mesodermal ones. Anterior regeneration as we have seen above proceeds differently from posterior regeneration. There is no sequential addition as a fixed number of anterior segments are regenerated. Presumably, no teloblasts are involved in anterior regeneration.

\section{Conclusion}

One of the goals of this review is to emphasize the necessity for 
studying a diversity of model species strategically located in the annelid tree. This is necessary in order to analyse experimentally the process of segment formation in all its complexity. We have seen that teloblasts are for example much more accessible to experimentation in the Clitellates because of their big size. On the other hand, no single annelid species can be described as a living fossil whose anatomy and mode of development would be identical to the last common ancestor of the annelids. All extant species are a mix of ancestral and derived characteristics. Clearly, the leeches are derived in many aspects of their morphology and development. The study of posterior addition in species of marine annelids such as Platynereis or Capitella will bring us valuable information to reconstitute the ancestral mode of segment formation in annelids and be able to compare it in a useful way to other bilaterian species.

A number of important questions will have to be addressed in the coming years that are relevant to the question of the evolution of segmentation in animals as a whole:

- teloblasts are a very specific type of stem cells with distinctive molecular signatures including conserved stem cell genes (mostly RNA binding protein genes) and teloblast-specific genes (mostly transcription factors). These signatures provide a potentially powerful and quick way of investigating the presence of teloblast-like cells in other species. For example, the existence of small teloblasts can be predicted in the posteriorly growing juveniles of earthworms. More broadly, there are species that present posterior addition in a number of bilaterian groups. This is the case of course in many arthropod groups. Insects, chelicerates and a number of crustacean groups show posterior addition during embryogenesis but post-embryonic posterior addition is also present in a number of crustaceans and myriapods. Interestingly, malacostracan crustaceans are the only group outside clitellate annelids that are also known to build their anterior/posterior axis through the activity of big embryonic teloblasts. These crustacean teloblasts could have evolved under the same sort of selection pressure as described above for the clitellate big teloblasts. There are also bilaterian groups in which an elongated axis is built through posterior addition of tissues but without segment formation. This is the case for example in nemerteans (spiralians) and in enteropneusts (deuterostomes). It would be interesting to investigate whether teloblast-like cells also exists in these groups.

- Is there a "segment formation clock" in annelids? A segment formation clock is an autonomous periodic mechanism taking place in the cells of the SAZ and determining segmental periodicity. Again, given the divergence that exists among annelid groups, the answer to this question cannot be a simple one. We can speculate theoretically in two divergent groups: the leeches and Platynereis. In the leeches, the production of segmental periodicity is completely dependent on the regular activity of the teloblasts during embryogenesis. Primary blast cells, founder cells of the segment, are produced at regular time intervals, in the same way as somites in vertebrates. The segment formation clock and the cell cycle clock of the teloblasts are thus intertwined in the leech. The answer to the above question has to be a positive one in leeches. In Platynereis and in most post-embryonic growing annelids, the answer will be different because segments are not produced at regular time intervals. The rate of segment production varies notably in function of the metabolic rate of the animal. This is already quite obvious in small three-segment juveniles in which the fourth segment and the following ones are produced at considerably variable time in different worms, possibly as a result of the efficiency of food intake. Thus, irrespective of the mechanisms for creating segmental periodicity in Platynereis, they cannot be qualified as a "clock" which, by definition, has to be ticking regularly and autonomously. Instead, Platynereis must have a non-autonomous regulated oscillator possibly working in the small teloblast cells or in a neighbouring tissue such as the pygidial ectoderm (Fig. $8 \mathrm{E}$ and F). This situation is likely to be the ancestral one in annelids. Embryonic segment formation clocks, as they are shown to exist in vertebrates and are suggested to exist in insects (Sarrazin et al., 2012) and in clitellate annelids (above) have to be derived mechanisms in this reasoning.

\section{Acknowledgments}

The author wishes to thank Greg Rouse for discussing some aspects of this review as well as two anonymous referees for valuable comments. The author is supported by the CNRS, the Universite Paris-Diderot, by a grant from the LABEX "Who Am I?" and by a grant of the Agence Nationale de la Recherche (ANR Blanc "METAMERE").

\section{References}

ACKERMANN, C., DORRESTEIJN, A. and FISCHER A. (2005) Clonal domains in postlarval Platynereis dumerilii(Annelida: Polychaeta). J Morphol. 26: 6258-6280.

AKESSON, B. (1968) The embryology of the Polychaete Eunice kobiensis. Acta Zool. 48: 142-192

ALLEN, M.J. (1959) Embryological development of the polychaetous annelid, Diopatra cuprea (Bose). Biol. Bull. 116: 339-361.

ALLEN, M.J. (1964) Embryological development of the syllid, Autolytus fasciatus (Bose) (Class Polychaeta). Biol. Bull. 127: 187-205.

ANDERSON, D.T. (1959) The Embryology of the Polychaete Scoloplos armiger. Q. J. Microsc. Sci. 100: 89-166.

BAKALENKO, N.I., NOVIKOVA, E.L., NESTERENKO, A.Y. and KULAKOVA, M.A. (2013) Hox gene expression during postlarval development of the polychaete Alitta virens. Evodevo. 4: 13.

BALAVOINE, G. and ADOUTTE, A. (2003) The segmented urbilateria: a testable scenario. Integr Comp Biol. 43: 137-147.

BELY, A.E. (1999). Decoupling of fission and regenerative capabilities in an asexual oligochaete. Hydrobiologia 406: 243-251.

BELY, A.E. (2006) Distribution of segment regeneration ability in the Annelida. Integr Comp Biol. 46: 508-518.

BENAZERAF, B. and POURQUIE, O. (2013) Formation and segmentation of the vertebrate body axis. Annu Rev Cell Dev Biol. 29: 1-26.

BERRILL, N.J. (1955) The origins of vertebrates. Oxford Univ. Press, Oxford.

BHAUD, M. and CAZAUX, C. (1987). Description and identification of polychaete larvae; their implications in current biological problems. Oceanis 13: 596-753.

BOUCHE, M.L., ARNOULT, F. and VERNET, G. (2003) Caudal regeneration in Tubifex tubifex (Oligochaeta, Tubificidae) following copper exposure. Invertebrate Biol. 122: 42-51.

BLAKE, J.A. (1975a). The larval development of Polychaeta from the northern California coast. 1. Cirriformia spirabrancha (family Cirratulidae). Trans. Amer. Micros. Soc. 94: 179-188.

BLAKE, J.A. (1975b) The larval development of Polychaeta from the northern California Coast. III. Eighteen species of Errantia. Ophelia 14: 23-84.

BLAKE, J.A. (1980). The larval development of Polychaeta from the Northern California coast. IV. Leitoscoloplos pugettensis and Scoloplos acmeceps (Family Orbiniidae). Ophelia 19: 1-18.

BLAKE, J.A. and ARNOFSKY, P.L. (1999) Reproduction and larval development of the Spioniform Polychaeta with application to systematics and phylogeny. Hydrobiologia 402: 57-106.

BUDD, G.E. (2001) Why are arthropods segmented? Evol Dev. 3: 332-342. 
CAZAUX, C. (1970) Recherches sur l'écologie et le développement larvaire des polychètes de la région d'Arcachon. Thèse d'état, Université de Bordeaux.

CRUMRINE, L. (2001) in An identification guide to the larval marine invertebrates of the Pacific northwest. Shanks A (ed). Oregon State University Press. pp 39-77.

CUVIER, G. (1817): Le règne animal. Vol. II. 532 pp., Déterville, Paris.

DAMEN, W.G. (2007) Evolutionary conservation and divergence of the segmentation process in arthropods. Dev Dyn. 236: 1379-1391.

DE ROSA, R., PRUD'HOMME, B. and BALAVOINE G. (2005) Caudal and evenskipped in the annelid Platynereis dumerilii and the ancestry of posterior growth. Evol Dev. 7: 574-587.

DILL, K.K. and SEAVER, E.C. (2008) Vasa and nanos are coexpressed in somatic and germ line tissue from early embryonic cleavage stages through adulthood in the polychaete Capitella sp. I. Dev Genes Evol. 218: 453-463.

DRAY, N., TESSMAR-RAIBLE, K., LE GOUAR, M., VIBERT, L., CHRISTODOULOU, F., SCHIPANY, K., GUILLOU, A., ZANTKE, J., SNYMAN, H., BEHAGUE, J., et al. (2010) Hedgehog signaling regulates segment formation in the annelid Platynereis. Science. 329: 339-342

DUNN, C.W., HEJNOL, A., MATUS, D.Q., PANG, K., BROWNE, W.E., SMITH, S.A., SEAVER, E., ROUSE, G.W., OBST, M., EDGECOMBE, G.D. et al. (2008) Broad phylogenomic sampling improves resolution of the animal tree of life. Nature 452: 745-749.

EECKAUT, I. (2003) Larval Development of Myzostoma cirriferum. (Myzostomida). J. Morphol. 258: 269-283.

FARKE, H. and BERGHUIS, E.M. (1979) Spawning, larval development and migration of Arenicola marine under field conditions in the western Wadden Sea. Neth. J. Sea Res. 13: 529-535.

FISCHER, A. and DORRESTEIJNA. (2004) The polychaete Platynereis dumerilii(Annelida): a laboratory animal with spiralian cleavage, lifelong segment proliferation and a mixed benthic/pelagic life cycle. Bioessays. 26: 314-325.

FISCHER, A.H., HENRICH, T. and ARENDT, D. (2010) The normal development of Platynereis dumerilii (Nereididae, Annelida). Front Zool. 7: 31.

FISCHER, A.H. and ARENDT, D. (2013) Mesoteloblast-like mesodermal stem cells in the polychaete annelid Platynereis dumerilii (Nereididae). J Exp Zool B Mol Dev Evol. 320: 94-104.

FRANKE, H.D. (1999) Reproduction of the Syllidae (Annelida: Polychaeta). Hydrobiologia 402: 39-55.

FRÖBIUS, A.C., MATUS, D.Q. and SEAVER, E.C. (2008) Genomic organization and expression demonstrate spatial and temporal Hox gene colinearity in the lophotrochozoan Capitella sp. I. PLoS One. 3: e4004.

GAZAVE, E., BEHAGUE, J., LAPLANE, L., GUILLOU, A., PREAU, L., DEMILLY, A., BALAVOINE, G. and VERVOORT, M. (2013) Posterior elongation in the annelid Platynereis dumerilii involves stem cells molecularly related to primordial germ cells. Dev Biol. 382: 246-267.

GIANI, V.C. Jr, YAMAGUCHI, E., BOYLE, M.J. and SEAVER, E.C. (2011) Somatic and germline expression of piwi during development and regeneration in the marine polychaete annelid Capitella teleta. Evodevo. 2: 10.

GARSTANG, W. (1928) The morphology of the Tunicata, and its bearing on the phylogeny of the Chordata. Q. J. Microsc. Sci. 72: 51-187.

GATES, G.E. (1950) Regeneration in the earthworm, Eisenia foetida, Savigny, 1826; posterior regeneration. Biol Bull. 98: 36-45.

GATES, G.E. (1949) Regeneration in an earthworm, Eisenia foetida (Savigny) 1826; anterior regeneration. Biol Bull. 96: 129-139.

GIBSON, G. and HARVEY, J. (2000) Morphogenesis during asexual reproduction in Pygospio elegans Claparede (Polychaeta, Spionidae). Biol. Bull. 199: 41-49.

GIBSON, P.H. and CLARK, R.B. (1976) Reproduction of Dodecaceria caulleryi (Polychaeta: Cirratulidae). J. Mar. Bioi. Assn. U.K. 56: 649-674.

GOTO, A., KITAMURA, K., ARAI, A. and SHIMIZU, T. (1999) Cell fate analysis of teloblasts in the Tubifex embryo by intracellular injection of HRP. Dev Growth Differ. 41: 703-713.

HEJNOL, A. and MARTINDALE, M.Q. (2008) Acoel development supports a simple planula-like urbilaterian. Philos Trans R Soc Lond B Biol Sci. 363: 1493-1501.

HEJNOL, A., OBST, M., STAMATAKIS, A., OTT, M., ROUSE, G.W., EDGECOMBE, G.D., MARTINEZ, P., BAGUÑA, J., BAILLY, X., JONDELIUS, U.et al. (2009) Assessing the root of bilaterian animals with scalable phylogenomic methods. Proc
Biol Sci. 276: 4261-4270.

HESSLING, R. and WESTHEIDE, W. (2002) Are Echiura derived from a segmented ancestor? Immunohistochemical analysis of the nervous system in developmenta stages of Bonellia viridis. J Morphol. 25: 100-113.

HYMAN, L.H. (1951) The Invertebrates. II Platyhelminthes and Rhynchocoela. The Acoelomate Bilateria. McGraw-Hill, New York.

IRVINE, S.Q., CHAGA, O. and MARTINDALE, M.Q. (1999) Larval Ontogenetic Stages of Chaetopterus: Developmental Heterochrony in the Evolution of Chaetopterid Polychaetes. Biol. Bull. 197: 319-331.

JULIANO et al. (2010).

KOLBASOVA, G.D., TZETLIN, A.B. and KUPRIYANOVA, E.K. (2013) Biology of Pseudopotamilla reniformis (Müller 1771) in the White Sea, with description of asexual reproduction. Invertebr. Reprod. Dev. 57: 264-275.

KUDENOV, J.D. (1974) The reproductive biology of Eurythoe complanata (Pallas, 1766), (polychaeta: amphinomidae). PhD thesis.

KUPRIYANOVA, E.K., NISHI, E., TEN HOVE, H.A. and RZHAVSKY, A.V. (2001) Life history patterns in serpulimorph polychaetes: ecological and evolutionary perspectives. Oceanogr. mar. biol. Ann. Rev. 39: 1-101.

LANG, S.A. and SHAIN, D.H. (2009) Stem cell genesis and differentiation in leech. In Annelids in modern biology. (ed DH Shain). John Wiley and Sons. pp 116-132.

MCHUGH, D. (1993) A comparative study of reproduction and development in the Polychaete family Terebellidae. Biol. Bull. 185: 153-167.

MENDEZ, N., LINKE-GAMENICK, I. and FORBES, V.E. (2000) Variability in reproductive mode and larval development within the Capitella capitata species complex. Invertebr. Reprod. Dev 38: 131-142

MEYER, N.P. and SEAVER, E.C. (2010) Cell lineage and fate map of the primary somatoblast of the polychaete annelid Capitella teleta. Integr Comp Biol. 50:756-767.

MÜLLER, M.C. (2004) Nerve development, growth and differentiation during regeneration in Enchytraeus fragmentosus and Stylaria lacustris (Oligochaeta). Dev Growth Differ. 46: 471-478.

MYOHARA, M. (2012) What role do annelid neoblasts play? A comparison of the regeneration patterns in a neoblast-bearing and a neoblast-lacking enchytraeid oligochaete. PLoS One. 7: e37319.

NAKAMOTO, A., ARAI, A. and SHIMIZU, T. (2000) Cell lineage analysis of pattern formation in the Tubifex embryo. II. Segmentation in the ectoderm. Int $J$ Dev Biol. 44: 797-805.

NISHI, E. and NISHIHIRA, M. (1994). Colony formation via sexual and asexual reproduction in Salmacina dysteri. Zool. Sci.11: 589-595.

OSBORN, K.J., HADDOCK, S.H., PLEIJEL, F., MADIN, L.P. and ROUSE, G.W (2009) Deep-sea, swimming worms with luminescent "bombs". Science. 325: 964

PEEL, A.D., CHIPMAN, A.D. and AKAM, M. (2005) Arthropod segmentation: beyond the Drosophila paradigm. Nat Rev Genet. 6: 905-916.

PERNET, B. (2001) Escape Hatches for the Clonal Offspring of Serpulid Polychaetes. Biol. Bull. 200: 107-117.

PFEIFER, K., DORRESTEIJN, A.W. and FRÖBIUS, A.C. (2012) Activation of Hox genes during caudal regeneration of the polychaete annelid Platynereis dumerilii. Dev Genes Evol. 222: 165-179.

PICK, K.S., PHILIPPE, H., SCHREIBER, F., ERPENBECK, D., JACKSON, D.J., WREDE, P., WIENS, M., ALIE, A., MORGENSTERN, B., MANUEL, M. and WÖRHEIDE, G. (2010) Improved phylogenomic taxon sampling noticeably affects nonbilaterian relationships. Mol Biol Evol. 27: 1983-1987.

PIRES, A., GENTIL, F., QUINTINO, V. and RODRIGUES, A.M. (2012) Reproductive biology of Diopatra neapolitana (Annelida, Onuphidea), an exploited natura resource in Ria de Aveiro (northwestern Portugal). Marine Ecology 33: 56-65.

PALMEIRIM, I., HENRIQUE, D., ISH-HOROWICZ, D. and POURQUIE, O. (1997) Avian hairy gene expression identifies a molecular clock linked to vertebrate segmentation and somitogenesis. Cell. 91: 639-648.

PEEL, A.D., CHIPMAN, A.D. and AKAM, M. (2005) Arthropod segmentation: beyond the Drosophila paradigm. Nat Rev Genet. 6: 905-916.

REBSCHER, N., ZELADA-GONZALEZ, F., BANISCH, T.U., RAIBLE, F. and ARENDT, D. (2007) Vasa unveils a common origin of germ cells and of somatic stem cells from the posterior growth zone in the polychaete Platynereis dumerilii. Dev Biol. 306: 599-611.

RICE, M.E. (1970)Asexual reproduction in a sipunculid worm. Science 167: 1618-1620 
RICHARDS, T.L. (1967) Reproduction and development of the polychaete Stauronereis rudolphi, including a summary of development in the superfamily Eunicea. Marine Biol. 1: 124-133.

RICHMOND, D.L. and OATES, A.C. (2012) The segmentation clock: inherited trait or universal design principle? Curr Opin Genet Dev. 22: 600-606.

ROUSE, G.W. (2000) The epitome of hand waving? Larval feeding and hypotheses of metazoan phylogeny. Evol Dev. 2: 222-333.

ROUSE, G.W. and GAMBI, M.C. (1998) Evolution of reproductive features and larval development in the genus Amphiglena (Polychaeta: Sabellidae). Marine Biol. 131: 743-753.

SARRAZIN, A.F., PEEL, A.D. and AVEROF, M. (2012) A segmentation clock with two-segment periodicity in insects. Science. 336: 338-341.

SEAVER, E.C., THAMM, K. and HILL, S.D. (2005) Growth patterns during segmentation in the two polychaete annelids, Capitella sp. I and Hydroides elegans: comparisons at distinct life history stages. Evol Dev. 7: 312-326.

SEAVER, E.C., YAMAGUCHI, E., RICHARDS, G.S. and MEYER, N.P. (2012) Expression of the pair-rule gene homologs runt, Pax3/7, even-skipped-1 and even-skipped-2 during larval and juvenile development of the polychaete annelid Capitella teleta does not support a role in segmentation. Evodevo. 18: 8.

SHANKLAND, M. (1991) Leech segmentation: cell lineage and the formation of complex body patterns. Dev Biol 144: 221-231.

SHANKLAND, M. and SAVAGE, R.M. (1997) Annelids, the segmented worms. In Embryology, Constructing the Organism. (Eds S.F. Gilbert and A.M. Raunio). Sinauer Associates, Inc., Sunderland, MA. pp 219-235.

SOUTHWARD, E.C. (1999) Development of Perviata and Vestimentifera (Pogonophora). Hydrobiologia 402: 185-202.
STRUCK, T.H., PAUL, C., HILL, N., HARTMANN, S., HÖSEL, C., KUBE, M., LIEB B., MEYER, A., TIEDEMANN, R., PURSCHKE, G. and BLEIDORN, C. (2011) Phylogenomic analyses unravel annelid evolution. Nature. 471: 95-98.

STRUCK, T.H. (2011) Direction of evolution within Annelida and the definition of Pleistoannelida. J Zool Syst Evol Res 49: 340-345.

SUGIO, M., YOSHIDA-NORO, C., OZAWA, K. and TOCHINAI, S. (2012) Stem cells in asexual reproduction of Enchytraeus japonensis (Oligochaeta, Annelid): proliferation and migration of neoblasts. Dev. Growth Differ. 54: 439-450.

UCHIDA, H., TANASE, H. and KUBOTA, S. (2009) an extraordinarily large specimen of the polychaete worm Eunice aphroditois (Pallas) (order eunicea) from Shirahama, Wakayama, central Japan. Kuroshio Biosphere 5: 9-15

WANNINGER, A. and HASZPRUNAR, G. (2002) Chiton myogenesis: perspectives for the development and evolution of larval and adult muscle systems in molluscs. J Morphol. 251: 103-113.

WANNINGER, A., KRISTOF, A. and BRINKMANN, N. (2009) Sipunculans and segmentation. Commun Integr Biol. 2009: 56-59.

WEIGERT, A., HELM, C., MEYER, M., NICKEL, B., ARENDT, D., HAUSDORF, B., SANTOS, S.R., HALANYCH, K.M., PURSCHKE, G., BLEIDORN, C. and STRUCK, T.H. (2014) Illuminating the Base of the Annelid Tree Using Transcriptomics. Mol Biol Evol. 31: 1391-1401.

WILSON, D.P. (1936) Notes on the early stages of two polychaetes, Nephtys hombergi Lamarck and Pectinaria koreni Malmgren. J. Mar. Biol. Assn. U.K. 21: 305-310.

WILSON, W.H. (1991) Sexual reproductive modes in polychaetes: Classification and diversity. Bulletin of marine science. 48: 500-516.

ZATTARA, E.E. and BELY, A.E. (2011) Evolution of a novel developmental trajectory fission is distinct from regeneration in the annelid Pristina leidyi. Evol Dev. 13:80-95. 


\section{Further Related Reading, published previously in the Int. J. Dev. Biol.}

Brachyury, Tbx2/3 and sall expression during embryogenesis of the indirectly developing polychaete Hydroides elegans Cesar Arenas-Mena

Int. J. Dev. Biol. (2013) 57: 73-83

Hydra, a model system to trace the emergence of boundaries in developing eumetazoans Angelika Böttger and Monika Hassel Int. J. Dev. Biol. (2012) 56: 583-591

The head organizer in Hydra

Hans R. Bode

Int. J. Dev. Biol. (2012) 56: 473-478

Planarian embryology in the era of comparative developmental biology José M. Martín-Durán, Francisco Monjo and Rafael Romero Int. J. Dev. Biol. (2012) 56: 39-48

Planarian regeneration: a classic topic claiming new attention

Emili Saló and Kiyokazu Agata

Int. J. Dev. Biol. (2012) 56: 1-4

Function and specificity of Hox genes

David Foronda, Luis F. de Navas, Daniel L. Garaulet and Ernesto Sánchez-Herrero

Int. J. Dev. Biol. (2009) 53: 1409-1419

Segmentation, metamerism and the Cambrian explosion

Juan Pablo Couso

Int. J. Dev. Biol. (2009) 53: 1305-1316

A history of Evo-Devo research in Spain

Jaume Baguñà

Int. J. Dev. Biol. (2009) 53: 1205-1217

The first bilaterian organisms: simple or complex? New molecular evidence J Baguna, I Ruiz-Trillo, J Paps, M Loukota, C Ribera, U Jondelius, M Riutort Int. J. Dev. Biol. (2001) 45: S133-S134

Characterization of novel F-actin envelopes surrounding nuclei during cleavage of a polychaete worm.

S Jacobsohn

Int. J. Dev. Biol. (1999) 43: 19-26

5 yr ISI Impact Factor $(2011)=2.959$
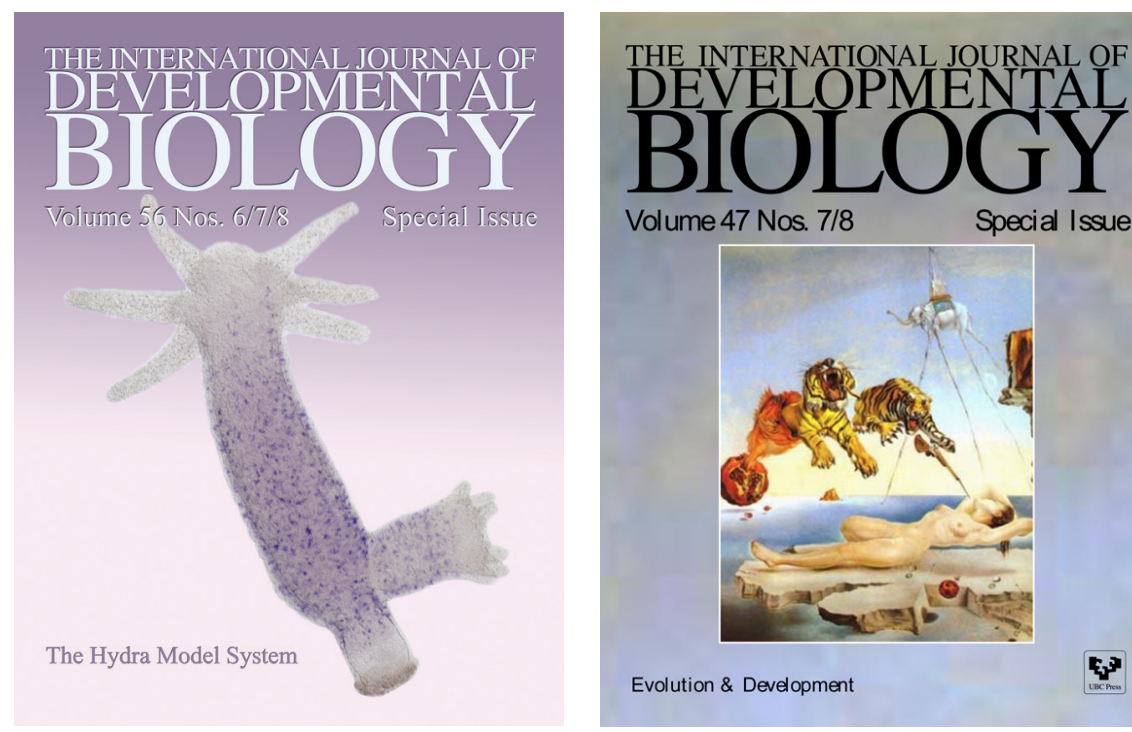

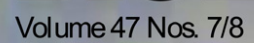

Special Issue

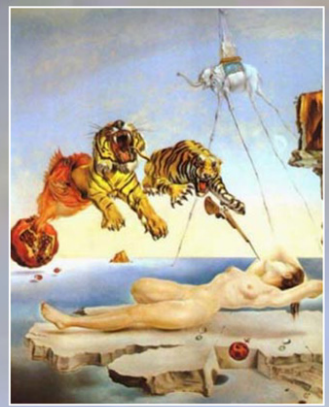

Evolution \& Development
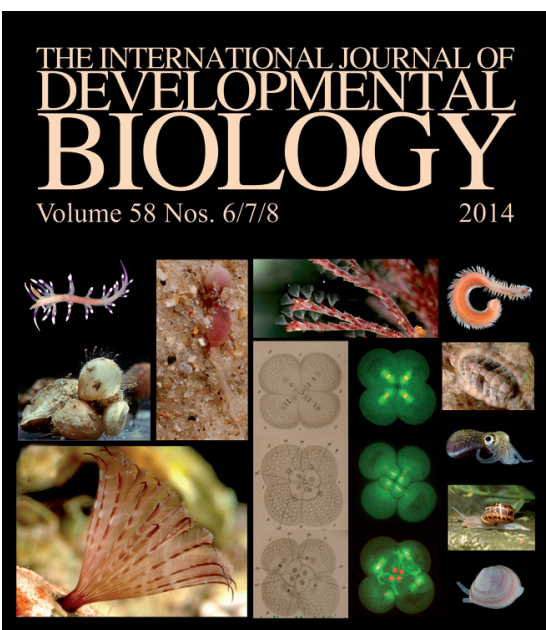

Spiralian Model Systems
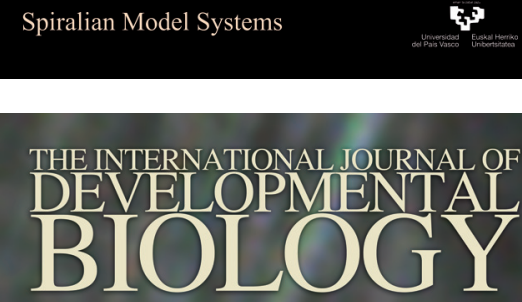

Volume 56 Nos. $1 / 2 / 3$

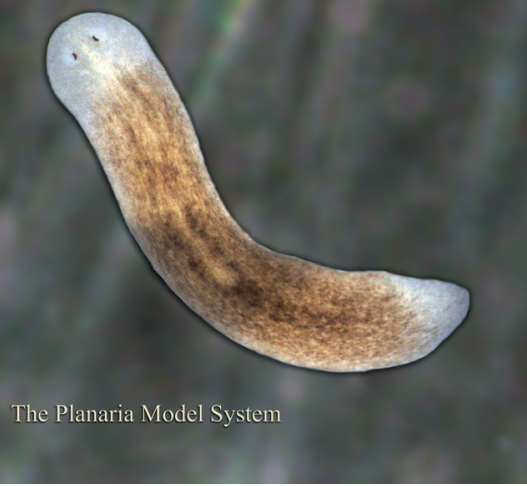

